\title{
Lentiviral Vector-Mediated Gene Transfer and RNA Silencing Technology in Neuronal Dysfunctions
}

\author{
Jean-Luc Dreyer
}

Published online: 23 September 2010

(C) Springer Science+Business Media, LLC 2010

\begin{abstract}
Lentiviral-mediated gene transfer in vivo or in cultured mammalian neurons can be used to address a wide variety of biological questions, to design animals models for specific neurodegenerative pathologies, or to test potential therapeutic approaches in a variety of brain disorders. Lentiviruses can infect non-dividing cells, thereby allowing stable gene transfer in post-mitotic cells such as mature neurons. An important contribution has been the use of inducible vectors: the same animal can thus be used repeatedly in the doxycycline-on or -off state, providing a powerful mean for assessing the function of a gene candidate in a disorder within a specific neuronal circuit. Furthermore, lentivirus vectors provide a unique tool to integrate siRNA expression constructs with the aim to locally knockdown expression of a specific gene, enabling to assess the function of a gene in a very specific neuronal pathway. Lentiviral vector-mediated delivery of short hairpin RNA results in persistent knockdown of gene expression in the brain. Therefore, the use of lentiviruses for stable expression of siRNA in brain is a powerful aid to probe gene functions in vivo and for gene therapy of diseases of the central nervous system. In this chapter I review the applications of lentivirus-mediated gene transfer in the investigation of specific gene candidates involved in major brain disorders and neurodegenerative processes. Major applications have been in polyglutamine disorders, such as synucleinopathies and Parkinson's disease, or in investigating gene function in Huntington's disease, dystonia, or muscular dystrophy. Recently, lentivirus gene transfer has been an invaluable tool for evaluation of gene function in
\end{abstract}

J.-L. Dreyer $(\bowtie)$

Division of Biochemistry, Department of Medicine, University of Fribourg, Rue du Musée 5, 1700 Fribourg, Switzerland e-mail: jean-luc.dreyer@unifr.ch behavioral disorders such as drug addiction and attentiondeficit hyperactivity disorder or in learning and cognition.

Keywords miRNA $\cdot$ Lentivirus - Brain diseases - Gene therapy $\cdot$ mRNA silencing

\section{Introduction}

Lentiviral vectors are increasingly used for gene delivery to neurons and in experimental models of neurodegeneration. Tackling neurodegenerative diseases represents a formidable challenge for our aging society $[1,2]$. Local delivery of therapeutic molecules represents one of the limiting factors for the treatment of neurodegenerative disorders. Gene transfer methods for efficient co-expression of exogenous proteins in neurons are crucial tools toward the understanding of the molecular basis of the central nervous system. In vivo gene transfer using lentiviral vectors constitutes a powerful tool in this area [3]. Major advantages of lentiviral vectors are their ability to transduce nondividing cells including differentiated neurons and to confer long-term expression of transgenes [4, 5].

In recent years, the breakthrough discovery that doublestranded RNA of 21 nucleotides in length (referred to as short or small interfering RNA; siRNA) triggers sequencespecific gene silencing in mammalian cells led to the development of a powerful new approach to study gene function [6-8]. This evolutionarily conserved mechanism is carried out by an endogenous pathway that centers on the use of endogenously encoded small RNAs, and can be hijacked to knockdown the expression of any target protein by introducing a specific siRNA into a cell [9]. Therefore, the ability to manipulate the RNA-induced interference (RNAi) in mammalian cells provided a very powerful tool to 
influence gene expression. Stable knockdown can be obtained by constitutive expression of the siRNA from the host chromosome, but neurons represent a cell type that display resistance to transduction by siRNAs, when attempting to silence expression of endogenous genes in these postmitotic cells. Thus for in vivo applications, RNAi has been hampered until recently by inefficient delivery methods and by the transient nature of the gene suppression. However, lentivirus-mediated expression of short hairpin (sh)RNA was shown to be long-term and mediate stable RNAi in a dose-dependent manner [10], therefore, providing a convenient way to integrate RNAi expression constructs. Besides their ability to infect non-dividing cells, thereby allowing knockdown in mature neurons, lentiviruses also improve the efficiency of gene delivery to different cell types, thus improving the potential usefulness of RNAi as therapy [10-14]. A number of lentiviral vectors have been developed for performing sh-directed RNAi in mice [13, 1518]. Some vectors encode green fluorescent protein (GFP) as a marker for infectivity and to track the RNAi knockdown cells in real time. Other vectors contain antibiotic selection markers, such as puromycin, which are useful when the cell selection is imposed. In addition, there are conditional versions of lentiviral RNAi vectors available, where the user may opt to "turn on" or "turn off" RNAi during the course of experimentation [4, 15, 18]. Drug-inducible systems allowing the control of transgene expression and knockdown in mammalian cells are invaluable tools for genetic research, and could also play important roles in translational research or gene therapy [19]. A lentivector-based, conditional gene expression system for drug-controllable expression of transgenes and shRNAs has been established that is highly robust and versatile, governing tightly controlled expression of transgenes and endogenous cellular genes in various primary and established cell lines in vitro, as well as in vivo in the central nervous system [19]. The Woodchuck hepatitis virus (WHV) posttranscriptional regulatory element (WPRE) facilitates nucleocytoplasmic transport of RNA mediated by several alternative pathways that may be cooperative and this element has been included in many different genetherapy vectors including lentivirus, AAV, adenovirus etc., to stimulate heterologous cDNAs expression. More recently, insertion of two copies of a human synapsin promoter/WPRE cassette in a single lentiviral vector was shown to direct robust co-expression of cDNAs in cultured neurons, while excluding expression in the surrounding glial cells [5]. In addition, insertion of the tetracycline-inducible system (Tet-off) controlled by the synapsin promoter results in tightly regulated expression of EGFP when used as a transgene in cultured neurons This tool provides neuron-specific and regulated expression mediated by single lentiviral vectors and will prove valuable tools for the study of neuronal function [5].
A major breakthrough in our understanding of specific gene function in many brain disorders has been made possible by either overexpressing or silencing gene expression in very specific neuronal pathways. For this purpose the use of replication uncompetent viruses, preventing the vector to spread away from the injection area, has been a major advance. Lentiviruses have the additional advantage that large gene can be inserted and permanently incorporated into the host cell. Furthermore, the use of neuron-specific promoters enables cell-specific gene transfer in a complex system such as the brain. In this review I will discuss the applications of lentivirus-mediated gene transfer in the investigation of a large variety of brain disorders, with particular emphasis of the use of lentiviruses for local gene knockdown.

\section{Multiple Sclerosis}

Multiple sclerosis (MS) is an autoimmune condition in which the immune system attacks the central nervous system, leading to demyelination [20, 21]. Disease onset usually occurs in young adults [22] with a prevalence that ranges between 2 and 150 per 100,000 [23]. Multiple sclerosis affects the white matter of the brain and spinal cord, destroying the myelin sheath and producing lesions (scleroses or plaques) in the white matter [22]. Although much is known about the mechanisms involved in the disease process, the cause remains unknown. Theories include genetics or infections [24]. It is not considered a hereditary disease; however, specific genes have been linked with multiple sclerosis [25] and genetics may play a role in determining a person's susceptibility to multiple sclerosis.

Differences in the human major histocompatibility complex increase the probability of suffering multiple sclerosis [26]. Besides, mutations in the IL-2RA and the IL-7RA subunits of the receptor for interleukin 2 and interleukin 7, respectively, are also associated with the disorder [27, 28]. The histocompatibility complex is involved in antigen presentation, while mutations in the IL-2 and IL-7 genes were already known to be associated with diabetes and other autoimmune conditions, supporting the notion that multiple sclerosis is an autoimmune disease [26, 29, 30]. Other studies have linked genes in chromosome 5 with the disease [31]. Richardson et al. [32] have used intrabody-mediated knockout of the high-affinity IL-2 receptor using a bicistronic lentivirus vector, but this has not yet been evaluated for the disease.

Furthermore, several studies demonstrate that lesions from patients contain activated transcription factors like NF- $\kappa$ B, STAT1, STAT3, and STAT6 [33-35], which can lead to enhanced signaling of inflammatory stimuli. Thus, 
regulation of inflammatory signaling may be altered in MS, and may be responsible for inflammatory demyelination. SHP-1 is a protein tyrosine phosphatase with two SH2 domains, which acts as a crucial negative regulator of cytokine signaling, inflammatory gene expression, and demyelination in central nervous system via STAT1, STAT3, and STAT6 [36-39]. Mice genetically lacking in SHP-1 (motheaten mice) display myelin deficiency, which may be mediated by increased inflammatory mediators in the CNS [40, 41]. Christophil et al. [42] established a role for SHP-1 in MS. The levels of SHP-1 protein and mRNA in PBMCs of patients were significantly lower compared to normal subjects. Moreover, promoter II transcripts, expressed from one of two known promoters, were selectively deficient in patients. As expected, patients had significantly higher levels of pSTAT6. Furthermore, siRNA to SHP-1 effectively increased the levels of phosphorylated pSTAT6 in PBMCs of controls to levels equal to patients. Christophil et al. [42] also designed a lentiviral vector expressing SHP-1 [43]. The vector carried the human SHP1 coding sequence, allowing the bicistronic expression of green fluorescent protein (GFP) and SHP-1 in the transduced cells. Transduction of PBMCs with this lentivirus lowered pSTAT6 levels. Multiple STAT6-responsive inflammatory genes were increased in PBMCs of patients relative to PBMCs of normal subjects. Thus, lentiviruses may be very efficient tools to assess the mechanisms of inflammatory demyelination.

\section{Dystonia}

Dystonia is a neurological movement disorder in which sustained muscle contractions cause twisting and repetitive movements or abnormal postures [44]. The disorder may be inherited or caused by other factors such as birth-related or other physical trauma, infection, poisoning (e.g., lead poisoning), or reaction to drugs. Primary dystonia is suspected to be caused by pathology of the central nervous system, likely originating in those parts of the brain concerned with motor function, such as the basal ganglia, and the GABA ( $\gamma$-aminobutyric acid) producing Purkinje neurons. Early onset generalized dystonia is a dominantly inherited disorder caused by neuronal dysfunction without an apparent loss of neurons. Most cases of the dominantly inherited movement disorder, early onset torsion dystonia (DYT1) are caused by a mutant form of torsinA. The same single mutation (GAG deletion) causes most cases, and results in loss of a Glutamine (Glu) in the carboxy terminal region of torsinA $(\Delta 302 / 303)$ [45]. Relatively little is understood about the normal function of torsinA or the physiological effects of the codon deletion associated with most cases of disease. TorsinA is an ATPase associated with diverse cellular activities (AAA) protein [46]. It is apparently involved in membrane structure/movement and processing of proteins through the secretory pathway and is located predominantly in the lumen of the endoplasmic reticulum (ER) [47, 48]. The mutant form of torsinA [torsin $\mathrm{A}(\Delta E)$ ] accumulates in the nuclear envelope (NE), leading to the formation of NE-derived membranous inclusions known as spheroid bodies that accumulate in the cytoplasm [49-51]. Overexpression of wild-type torsinA in cultured cells results in a reticular distribution of immunoreactive protein that co-localizes with endoplasmic reticulum resident chaperones, while the dystonia-related mutant form accumulates within concentric membrane whorls and nuclear-associated membrane stacks [52].

Recent studies suggest that the mutant form of torsinA carrying the disease-linked mutation, torsin $\mathrm{A}(\Delta E)$, acts through a dominant negative effect by recruiting wild-type torsin A into oligomeric structures in the nuclear envelope [53]. Therefore, suppressing torsin $\mathrm{A}(\Delta E)$ expression through RNAi could restore the normal function of torsinA(wt), representing a potentially effective therapy regardless of the biological role of torsinA [54]. GonzalezAllegre et al. [55] generated shRNAs that mediate allelespecific suppression of torsin $\mathrm{A}(\Delta E)$ and rescue cells from its dominant negative effect, restoring the normal distribution of torsinA(wt). In addition, delivery of this shRNA by a recombinant feline immunodeficiency virus effectively silenced torsin $\mathrm{A}(\Delta E)$ in a neural model of the disease. They established the feasibility of viral-mediated RNAi approach by demonstrating significant suppression of endogenous torsinA in mammalian neurons. Silencing of torsin A was achieved without triggering an interferon response. These results support the potential use of viralmediated RNAi as a therapy for DYT1 dystonia and establish the basis for preclinical testing in animal models of the disease. Further, to model the neuronal involvement, adult rat primary sensory dorsal root ganglion neurons in culture were infected with lentivirus vectors expressing human wild-type or mutant torsinA [56]. Expression of the mutant protein resulted in formation of torsinA-positive perinuclear inclusions. When the cells were co-infected with lentivirus vectors expressing the mutant torsinA message and a shRNA selectively targeting this message, inclusion formation was blocked. Vector-delivered siRNAs have the potential to decrease the adverse effects of this mutant protein in neurons without affecting wild-type protein.

A reduced rate of secretion is observed in primary fibroblasts from DYT1 patients expressing endogenous levels of torsinA and torsin $\mathrm{A}(\Delta E)$ when compared with control fibroblasts expressing only torsinA [47]. siRNA oligonucleotides have been used to downregulate the levels of torsin $\mathrm{A}$ or torsin $\mathrm{A}(\Delta E)$ mRNA and protein by over $65 \%$ 
following transfection. Transfection of siRNA for torsinA mRNA in control fibroblasts expressing Gaussia luciferase reduced levels of luciferase secretion compared with the same cells non-transfected or transfected with a non-specific siRNA. Transfection of siRNA selectively inhibiting torsin $\mathrm{A}(\Delta E)$ mRNA in DYT fibroblasts increased luciferase secretion when compared with cells non-transfected or transfected with a non-specific siRNA. Further, transduction of DYT1 cells with a lentivirus vector expressing torsin A, but not torsinB, also increased secretion [47], consistent with a role for torsin A as an ER chaperone affecting processing of proteins through the secretory pathway, and indicating that torsin $\mathrm{A}(\Delta E)$ acts to inhibit this torsin A activity. The ability of allele-specific siRNA for torsin $\mathrm{A}(\Delta E)$ to normalize secretory function in DYT1 patient cells supports its potential role as a therapeutic agent in early onset torsion dystonia.

\section{$\operatorname{Poly}(\mathbf{Q})$-Disorders}

There are at least nine human neurodegenerative disorders that are caused by polyglutamine extension, i.e., by expansion of the CAG trinucleotide repeat. RNAi has recently been performed on several prevalent polyglutamine diseases, e.g., spinobulbar muscular atrophy, Machado-Joseph disease, $\alpha$-synucleinopathies, Huntington's disease, and spinocerebellar ataxia.

Spinobulbar muscular atrophy is an X-linked motorneuron disease, related to CAG trinucleotide expansion in the first exon of the androgen receptor. It occurs at adulthood, and results in the loss of motorneurons in the lower spinal cord and the brain stem. Unaffected individuals have between 11 and 35 poly $(\mathrm{Q})$ repeats as opposed to 38 and 62 repeats in patients $[57,58]$. This poly $(\mathrm{Q})$ expansion results in intranuclear aggregates formation in tissues where the androgen receptor gene is normally expressed. Drosophila S2 cells were engineered to express a portion of human androgen receptor gene with CAG tracts of 26, 43, or 106 repeats tagged by green fluorescent protein (GFP) [59]. Cells carrying the CAG repeats of 43 and 106 developed GFP aggregates and aggresomes with 106 aggregates being formed much faster than $43 \mathrm{CAG}$ repeats. Using RNAi directed against the androgen receptor mRNA, Caplen et al. [59] showed loss of aggregates by $80 \%$ in co-transfected S2 cells.

Similarly, spinocerebellar ataxia type 1 is another poly $(\mathrm{Q})$ expansion disease, related to $\mathrm{CAG}$ repeats of ataxin-1 and characterized by slowly progressive incoordination of gait, and often associated with poor coordination of hands, speech, and eye movements, frequently resulting in cerebellar atrophy. Xia et al. [60] have also successfully suppressed these symptoms by
RNAi in a mouse model of this disease [60]. These studies show that RNAi interference could have considerable therapeutic potential in poly $(Q)$ neurodegenerative disorders.

Machado-Joseph disease (MJD) is a related ataxia and a fatal, dominant neurodegenerative disorder. MJD results from polyglutamine repeat expansion in the MJD-1 gene, conferring a toxic gain of function to the ataxin-3 protein. Overexpressing ataxin-3 in the rat brain using lentiviral vectors enabled to study the disorder in defined brain regions [61]. No neuropathological changes were observed upon wild-type ataxin-3 overexpression. Mutant ataxin-3 expression in striatum and cortex resulted in accumulation of misfolded ataxin-3, and within striatum, loss of neuronal markers. Striatal pathology was confirmed by observation of ataxin-3 aggregates in MJD transgenic mice and substantial reduction of the dopamine and cAMP regulated phosphoprotein (DARPP-32) immunoreactivity and, in human striata, by ataxin-3 inclusions, immunoreactive for ubiquitin and $\alpha$-synuclein [61]. This interesting study demonstrates the use of LV encoding mutant ataxin-3 to produce a model of MJD.

Synucleinopathies are caused by aggregates of $\alpha$-synuclein, due to polyglutamine extension of the mutated protein. The synuclein family includes three proteins, $\alpha$-synuclein, $\beta$-synuclein, and $\gamma$-synuclein, sharing a common, highly conserved motif with similarity to the class-A2 lipid-binding domains of apolipoproteins. Their function is poorly known so far, but $\alpha$-synuclein is mutated in several families with autosomal dominant Parkinson's disease [62]. $\alpha$-Synuclein is primarily found in neural tissue, where it is seen mainly in presynaptic terminals. It is predominantly expressed in the neocortex, hippocampus, substantia nigra, thalamus, and cerebellum. It is predominantly a neuronal protein, but can also be found in glial cells [63]. $\alpha$-Synuclein overexpression and its toxic accumulation in neurons or glia are known to play key roles in the pathogenesis of Parkinson's disease and other related neurodegenerative synucleinopathies. It can aggregate to form insoluble fibrils in these pathological conditions characterized by "Lewy bodies," such as Parkinson's disease, dementia with Lewy bodies, and multiple system atrophy. In addition, an $\alpha$-synuclein fragment, known as the nonAbeta component (NAC), is found in amyloid plaques in Alzheimer's disease.

In rare cases of familial forms of Parkinson's disease there is a mutation in the gene coding for $\alpha$-synuclein. Three point mutations have been identified thus far: A30P, E46K, and A53T, In addition, duplication and triplication of the gene appear to be the cause of Parkinson's disease in other lineages. Moreover, genetic variability of the $\alpha$-synuclein gene promoter is associated with idiopathic Parkinson's disease. 
To develop an animal model of PD, lentiviral vectors expressing different human or rat forms of $\alpha$-synuclein were injected into the substantia nigra of rats [64]. A selective loss of nigral dopaminergic neurons associated with a dopaminergic denervation of the striatum was observed in animals expressing either wild-type or mutant forms of human $\alpha$-synuclein. This neuronal degeneration correlates with the appearance of abundant $\alpha$-synucleinpositive inclusions and extensive neuritic pathology and recapitulates the essential neuropathological features of PD. The authors conclude that lentiviral-mediated genetic models may contribute to elucidate the mechanism of $\alpha$-synuclein-induced cell death, and allow the screening of candidate therapeutic molecules [64].

Silencing of the human $\alpha$-synuclein gene by vectorbased RNAi is a promising therapeutic approach for synucleinopathies. Fountaine and Wade-Martins [65] achieved $80 \%$ protein knockdown using siRNA targeted to endogenous $\alpha$-synuclein and showed that $\alpha$-synuclein suppression in vitro decreases dopamine transport and alters cellular dopamine homeostasis [65]. Sapru et al. reported a 21nucleotide sequence in the coding region of human $\alpha$-synuclein that constitutes an effective target for robust silencing by RNAi [66]. Using a dual cassette lentivirus that co-expresses an $\alpha$-synuclein-targeting shRNA and EGFP (as a marker gene), effective silencing of endogenous human $\alpha$-synuclein in vitro in the human dopaminergic cell line SH-SY5Y could be demonstrated and also in vivo silencing of experimentally expressed human $\alpha$-synuclein in rat brain could be achieved successfully [66]. This may provide the tools for developing effective gene silencing therapeutics for synucleinopathies, including Parkinson's disease.

$\alpha$-Synuclein inhibits tyrosine hydroxylase (TH), the rate limiting enzyme in catecholamine synthesis, which is frequently used as a marker of dopaminergic neuronal loss in animal models of Parkinson's disease (PD). TH is activated by the phosphorylation of key seryl residues in the $\mathrm{TH}$ regulatory-domain. $\alpha$-Synuclein reduces TH phosphorylation, which then reduces dopamine synthesis [67, 68]. Using wt human $\alpha$-synuclein lentivirus, Alerte et al. [69] transduced dopaminergic neurons in the olfactory bulb of $\alpha$-synuclein knockout mice and observed that cells bearing aggregated $\alpha$-synuclein, had significantly reduced total anti-TH immunoreactivity, but high phosphoserine-TH labeling, which suggests that aggregated $\alpha$-synuclein is no longer able to inhibit TH [69].

Huntington's disease is an autosomal dominant hereditary brain disorder that is progressive and fatal, caused by expansion of a CAG trinucleotide repeat in exon- 1 of the Huntingtin gene [70]. The precise function of huntingtin is unknown, but in mice, complete deletion of the huntingtin gene is lethal. Mutations in this gene result in involuntary movement (chorea), cognitive impairment and psychiatric problems such as depression and anxiety [71, 72]. This expansion elongates the $\mathrm{N}$-terminal poly $(\mathrm{Q})$ stretch of the protein, resulting in aggregation and the formation of neuronal intranuclear inclusions that causes an increase in the rate of neuronal cell death in select areas of the brain, affecting neurological functions [73, 74]. As Huntington's disease is a monogenetic disorder conclusively linked to a single gene, researchers investigated using gene knockdown and lentiviral-mediated gene transfer of mutated huntingtin as a potential treatment $[75,76]$. siRNA therapy achieved a $60 \%$ reduction in expression of the mutated protein in a mouse model and progression of the disease was stalled [77]. However, using RNA interference to treat Huntington's disease could have unexpected effects unless knockdown of the unmutated huntingtin protein can be avoided, since full deletion of the normal protein is lethal. Also off-target effects of siRNA must be avoided [78].

A lentiviral vector expressing a mutant huntingtin protein (htt171-82Q) was used to generate a chronic model of Huntington's disease (HD) in rat primary striatal cultures [79]. Primary striatal neurons expressing N-terminal fragments of mutant huntingtin in vitro (via lentiviral gene delivery) faithfully reproduce the gene expression changes seen in human patients and may serve as models of the disease [79-81]. Expression of a wild-type fragment of huntingtin (htt171-18Q) caused only a small number of RNA changes. The disease-related signal in huntingtin17182Q versus huntingtin171-18Q comparisons results in the differential detection of $20 \%$ of all mRNA probe sets [81]. Transcriptomic effects of mutated huntingtin 171 are timeand polyglutamine-length dependent, and occur in parallel with other manifestations of polyglutamine toxicity over 4-8 weeks. Specific changes in lentivirus-mediated huntingtin171-82Q-expressing striatal cells accurately recapitulated those observed in human patients and included decreases in specific mRNAs (proenkephalin, regulator of G-protein signaling-4, dopamine D1 and D2 receptors, cannabinoid CB1 receptor, and DARPP-32). This lentiviral-transfer study showed that induced dysregulation of the striatal transcriptome might be attributed to intrinsic effects of mutant huntingtin [81].

A new strategy based on lentiviral-mediated delivery of mutant huntingtin (htt) was used to create a genetic model of Huntington's disease (HD) in rats and to assess the relative contribution of polyglutamine (CAG) repeat size. Lentiviral vectors coding for the first 171,853 , and 1520 amino acids of wild-type (19 CAG) or mutant htt $(44,66$, and $82 \mathrm{CAG}$ ) driven by either the phosphoglycerate kinase 1 (PGK) or the cytomegalovirus (CMV) promoters were injected in rat striatum [82]. Lentiviral-mediated overexpression of mutated huntingtin expressing 82 polyglutamine residues protein led to proteolytic release of 
$\mathrm{N}$-terminal huntingtin fragments, nuclear aggregation, and a striatal dysfunction and accelerate the pathological process, as revealed by decrease of DARPP-32 staining but absence of the neuron-specific nuclear protein NeuN downregulation [83]. Heat-shock proteins, which refold denatured proteins, also mitigate Huntington's disease mice models; as a matter of fact, based on lentiviral-mediated overexpression of a mutated huntingtin fragment, Perrin et al. [84] showed that heat-shock proteins 104 and 27 rescue striatal dysfunction in primary striatal neuronal cultures and in vivo, in rat models, both chaperones significantly reduced mutated huntingtin-related loss of DARPP-32 expression [84]. Furthermore, the trophic factors CNTF (Ciliary Neurotrophic Factor) and BDNF (Brain-Derived Neurotrophic Factor) are neuroprotective in acute Huntiongton's models and prevent striatal degeneration in a chronic model. Results demonstrated that both agents were neuroprotective without modifying inclusion formation [79]. Lentiviral vectors expressing the human CNTF were injected in the striatum of wild-type and transgenic mice expressing full-length huntingtin with 72 CAG repeats; behavioral analysis showed increased locomotor activity in 5- to 6-month-old treated mice compared to wild-type animals [80]. Interestingly, CNTF expression reduced the activity levels of mice expressing mutated huntingtin compared to control animals. Thus, sustained striatal expression of CNTF can be achieved with lentiviruses [80]. By contrast intrastriatal lentiviral vector transfer of GDNF, performed at 5 weeks of age, does not ameliorate neurological and behavioral impairments in the R6/2 transgenic mice model of Huntington's disease [85].

Another hypothesis for the disease suggested that dopamine, found in high concentrations in the striatum, may play a role in striatal cell death by increasing the toxicity of an $\mathrm{N}$-terminal fragment of mutated huntingtin (Htt-171-82Q) [86, 87]. Stimulation of the dopamine D2 receptor (DR2) with haloperidol protects striatal neurons from dysfunction induced by mutated huntingtin [88]. Mutant huntingtin causes disruption of mitochondrial function by inhibiting expression of PGC- $1 \alpha$, i.e., a transcriptional co-activator that regulates several metabolic processes, including mitochondrial biogenesis and respiration, and lentiviral-mediated delivery of PGC- $1 \alpha$ in the striatum provides neuroprotection in the transgenic mice models [89]. Mitochondrial complex III-mediated modulation of huntingtin aggregates was observed in a neuronal progenitor RN33B cell line transduced by lentivirus carrying mutant huntingtin [90]. Mitochondrial complex II protein (mCII) levels are reduced in striatum of patients, notably the $30-\mathrm{kDa}$ iron-sulfur subunit and the $70-\mathrm{kDa}$ FAD subunit [86], indicating that this complex may be important for dopamine-mediated striatal cell death. Lentiviral-mediated expression of Htt171-82Q preferentially decreased the levels of these subunits in vitro and affected the dehydrogenase activity of the complex [86]. Dopamineinduced down-regulation of mCII levels can be blocked by several dopamine D2 receptor antagonists [87]. Lentiviralmediated overexpression of mCII subunits abrogated the effects of dopamine, both by high dopamine concentrations alone and neuronal death induced by low dopamine concentrations together with Htt-171-82Q [87]. Thus, lentiviral treatment enabled to explore a novel pathway that links dopamine signaling and regulation of mCII activity, and provides insights for a key role for oxidative energy in the disease.

\section{Parkinson's}

Parkinson's disease is characterized by a progressive loss of midbrain dopamine neurons and the presence of cytoplasmic inclusions called Lewy bodies. Several approaches have been developed using lentiviral-mediated gene transfer technologies [91-94]. Mutations in several genes have been linked to familiar Parkinson's, including $\alpha$-synuclein and parkin. Parkin is a protein that functions within a multiprotein E3 ubiquitin ligase complex, catalyzing the covalent attachment of ubiquitin moieties onto substrate proteins and thus promoting degradation of specific substrates in cells. It is characterized by its ubiquitinlike motive at the $\mathrm{N}$-terminus, and two RING fingers domains (RING I and RING II) and one "in-between RING finger motives" at the C-terminus [95]. Parkin may protect neurons against $\alpha$-synuclein toxicity, proteasomal dysfunction and kainate-induced excitotoxicity and may play a role in controlling neurotransmitter trafficking at the presynaptic terminal and in calcium-dependent exocytosis. The protein carries out its activity by polyubiquitinating substrates through its lysine 48 residue for proteasomedependent degradation [96], but it can also promote a proteasome-independent process by lysine 63-linked ubiquitination, which is a signal for ribosomal function, endocytosis of membrane proteins, protein sorting and trafficking [97, 98]. The loss of parkin's E3-ligase activity leads to dopaminergic neuronal degeneration in early onset autosomal recessive juvenile parkinsonism, suggesting a key role of parkin for dopamine neuron survival. Thus its overexpression may provide a novel strategy for neuroprotection in the disease [99]. In a rat lentiviral model of Parkinson's, animals overexpressing parkin showed significant reductions in $\alpha$-synuclein-induced neuropathology, including preservation of tyrosine hydroxylase-positive cell bodies in the substantia nigra [100]. The parkin-mediated neuroprotection was associated with an increase in hyperphosphorylated $\alpha$-synuclein inclusions, suggesting a key role for parkin in the genesis of Lewy bodies. 
As another approach, reactive oxygen species are considered to contribute to the pathogenesis of the disease. Therefore, antioxidative gene therapy strategies may be relevant as a therapeutical approach. Indeed, lentivirusmediated expression of the antioxidant enzyme glutathione peroxidase provides small but significant neuroprotection against drug-induced toxicity [101], and could be suitable as a potential neuroprotective approach. In addition, an abnormal accumulation of cytosolic dopamine resulting in reactive oxygen species and dopamine-quinone products plays an important role in the selective degeneration of substantia nigra pars compacta dopaminergic neurons in Parkinson's disease. The neuronal-specific vesicular monoamine transporter (VMAT2), responsible for uptake of dopamine into vesicles, has been shown to play a central role both in intracellular dopamine homeostasis and sequestration of dopaminergic neurotoxins. Lentivirusmediated transfection of VMAT2 increases intracellular dopamine content, augments potassium-induced dopamine release and attenuates cell death, and enhances vesicular dopamine storage [102]. The opposite was seen after downregulation of VMAT2 using virally delivered shRNAs [102].

Furthermore, growth factors such as glial cell linederived neurotrophic factor (GDNF) have been shown to prevent neurodegeneration and promote regeneration in many animal models of Parkinson's disease [103]. MPTP (1-methyl-4-phenyl-1,2,3,6-tetrahydropyridine) is a neurotoxin used to study the disease in animal models (mainly monkeys) that causes permanent symptoms of Parkinson's disease by killing certain neurons in the substantia nigra of the brain. MPTP is metabolized into the toxic cation 1-methyl-4-phenylpyridinium (MPP+) by the enzyme MAO-B of glial cells, which primarily kills dopamineproducing neurons in a part of the brain called the pars compacta of the substantia nigra. Infusion of recombinant human GDNF into the rat striatum markedly protected dopamine neurons against MPP+-induced toxicity [104], and thus GDNF is a good candidate agent for restoring functional reinnervation and/or neuroprotection of dopamine nigrostriatal system for the treatment of Parkinson's disease [94]. Recently, recombinant LVs were developed and used for effective GDNF gene delivery [3, 92-94, 105]. In vivo gene delivery of LV-GDNF has been widely investigated [106] and viral delivery of GDNF currently represents one of the most promising neuroprotective strategies for Parkinson's Disease [100]. However, one of the important unresolved issues for this strategy is the threshold number of dopamine (DA) nigral neurons and/or of striatal DA terminals necessary for optimal benefit from GDNF therapy [94]. Intracerebral injection of LV-GDNF into 6-hydroxy-dopamine (6-OHDA) lesioned rats [107110] and MPTP-treated monkeys [105, 111] resulted in persistent protection of the nigrostriatal DA pathway and recovery of motor function [93, 108, 109, 112, 113], thereby strongly supporting their application in the clinic. Intrastriatal neurotrophic effects of long-term GDNF delivery using a lentiviral vector restored complete striatal dopamine innervation in the previously denervated area, and this was associated with significant behavioral improvements in a model of early Parkinson's disease [94]. Apomorphine-induced rotation was significantly decreased in the LV-GDNF-injected group compared to control animals [3] and GDNF efficiently protected $69.5 \%$ of the tyrosine hydroxylase-positive cells in the substantia nigra against 6-hydroxydopamine-induced toxicity. LV-GDNF treatment induced substantial sprouting from surviving DA axons, in agreement with previous work [75, 105, 114]. Interestingly, aberrant sprouting was not observed, and consequently, negative functional effects such as those presented by animals with extensive sprouting in or adjacent to the substantia nigra [75, 109] were not observed. However, a rat model has been used which develops a progressive and selective loss of dopamine neurons associated with the appearance of $\alpha$-synuclein containing inclusions, thus recapitulating the major hallmarks of Parkinson's disease. In this model, a lentiviral vector coding for GDNF (lenti-GDNF) was tested for its ability to prevent nigral dopaminergic degeneration associated with the lentiviral-mediated expression of the A30P mutant human $\alpha$-synuclein (lenti-A30P). When injected in the substantia nigra 2 weeks before nigral administration of lenti-A30P, it induced robust expression of GDNF but did not prevent the $\alpha$-synuclein-induced dopaminergic neurodegeneration, indicating that sustained GDNF treatment cannot modulate the cellular toxicity related to abnormal protein accumulation [115]. Recently, however, in an encouraging primate study, Kordower et al. [105] injected LV-GDNF into striatum and substantia nigra 1 week after an intracarotid injection of the MPTP toxin, selectively damaging the dopamine system [103]. In 3 months, motor deficits were reversed and loss of $\mathrm{TH}$-positive neurons in the nigra had been prevented, while $\mathrm{TH}$-positive projections to the striatum were preserved. Thus, if GDNF is delivered at the lesion site before neurodegeneration progresses too far, LV-mediated GDNF treatments displays impressive efficiency and induces functional reinnervation, in both rodents and monkeys, which may provide a basis for new clinical trials [103].

Finally, as an alternative, human neural progenitor cells hold great potential as an ex vivo system for delivery of therapeutic proteins to the central nervous system. When cultured as aggregates (neurospheres), they are capable of significant in vitro expansion. Methods have been developed for lentiviral vector-mediated gene delivery into human neural progenitor cells that maintain their 
differentiation and proliferative properties, and result in long-term, stable expression, and these cells have been successfully transplanted into a rodent model of Parkinson's disease, inducing stable neuroprotection [116]. Using a similar approach, Ebert et al. [117] produced human neural progenitor cells releasing either GDNF or Insulinlike growth factor 1 (IGF-1) and transplanted them into a rat model of PD. IGF-1, like GDNF, is also known to have neuroprotective effects in a number of disease models but has not been extensively studied in models of PD. Progenitor cells secreting either GDNF or IGF-1 significantly reduced amphetamine-induced rotational asymmetry and dopamine neuron loss [117]. Interestingly, GDNF, but not IGF-1, was able to protect or regenerate TH-positive fibers in the striatum, whereas in contrast, IGF-1, but not GDNF, significantly increased the overall survival of progenitor cells both in vitro and following transplantation [117]. In areas of GDNF delivery increased TH- and VMAT2positive fibers (vesicular monoamine transporter 2) was also observed, which may regulate the sensitivity of rat dopaminergic neurons to disturbed cytosolic dopamine levels.

Together these studies show that lentiviral vectors constitute a powerful gene delivery system for the screening of therapeutic molecules in mouse models of Parkinson's disease $[3,91,118]$. Due to their impressive efficiency, time may now be ripe to explore these vector systems as tools for neuroprotective treatments in patients with Parkinson's disease [113].

\section{Alzheimer's Disease}

Alzheimer's disease is associated with the accumulation of insoluble plaques of amyloid protein (APP) in the central nervous system, as well as intracellular microfibrillar tangles, along with loss of cholinergic neurons projecting from the basal forebrain to the hippocampus and amygdala. Plaque deposition is a result of overproduction of amyloid$\beta$ protein (Abeta) through the activity of $\gamma$-secretase, of which the presenilins are thought to be a component. Early onset familial Alzheimer's, for example, is associated with mutations in presenilin genes PS1 and PS2 which lead to over secretion of Abeta. RNAi knockdown of PSN results in a blockage of $\gamma$-secretase activity [119]. Also siRNAs targeting the $\beta$-secretase, BACE1, were shown to reduce APP production in mouse cortical neurons, offering a potential therapeutic approach for AD [120]. Lentiviruses targeting selective genes involved in the disease have been very powerful in better clarifying their functions in the disorder.

Amyloid- $\beta$ protein (Abeta) is derived from APP by sequential cleavages of $\beta$ - and $\gamma$-secretases. The molecules responsible for these proteolytic activities have been identified [121]. The presenilin 1 and 2 are $\gamma$-secretase, and the identity of $\beta$-secretase has been shown to be the novel transmembrane aspartic protease, $\beta$-site APP cleaving enzyme 1 (BACE1; also called Asp2 and memapsin 2). BACE2, a protease homologous to BACE1, was also identified, and together the two enzymes define a new family of transmembrane aspartic proteases [121]. $\beta$-Site APP cleaving enzyme 1 (BACE1) is the major $\beta$-secretase in vivo. Burton [122] designed a number of siRNA target sequences and cloned them into lentivirus vectors and showed that RNA inhibition of $\beta$-secretase reverts Alzheimer's disease in mice [122]. Sierant et al. [123] designed lentivirus vector-encoded siRNAs for efficient knockdown of overexpressed and endogenous BACE1 in a rat brain and also the allele-specific siRNAs to silence the mutant presenilin 1 (L392V PS-1), the main component of $\gamma$-secretase. This results in strongly reducing the level of $\beta$-amyloid accumulation in the brain. These tools could be beneficial for potential therapeutic approach for treatment of the disease [123]. In another study, Singer et al. [124] targeted BACE1 with siRNAs. Lowering BACE1 levels using these lentiviral vectors expressing siRNAs targeting BACE1 reduced amyloid production and the neurodegenerative and behavioral deficits in APP transgenic mice, an approach that could have potential therapeutic value for treatment of the disease [124]. $\beta$-Site APP cleaving enzyme 2 (BACE2) is the homologue of BACE1 and cleaves APP at a novel theta site downstream of the $\alpha$ site, abolishing Abeta production [125]. Overexpression of BACE2 by lentivirus markedly reduced Abeta production in primary neurons derived from Swedish mutant APP transgenic mice. This suggests that therapeutic interventions that potentiate BACE2 may prevent AD pathogenesis [125]. Besides, El-Amouri et al. [126] targeted neprilysin (NEP), the dominant Abeta peptide-degrading enzyme in the brain. NEP becomes inactivated and down-regulated during both the early stages of $\mathrm{AD}$ and aging. Lentivirus-mediated overexpression of human NEP for 4 months in young APP/ $\triangle \mathrm{PS} 1$ double-transgenic mice resulted in reduction in $\mathrm{Ab}$ eta peptide levels, attenuation of amyloid load, oxidative stress, and inflammation, and improved spatial orientation. The overall reduction in amyloidosis and associated pathogenetic changes in the brain resulted in decreased memory impairment by approximately $50 \%$. Thus, restoring NEP levels in the brain at the early stages of $\mathrm{AD}$ is an effective strategy to prevent or attenuate disease progression. The cysteine protease cathepsin $\mathrm{B}(\mathrm{CatB})$ is also associated with amyloid plaques in $\mathrm{AD}$ brains and reduces levels of Abeta peptides, especially the aggregation-prone species. Lentivirus-mediated expression of CatB in aged hAPP mice reduced preexisting amyloid deposits [127], even thioflavin S-positive plaques. Under cell-free conditions, 
CatB effectively cleaved Abeta1-42, generating C-terminally truncated Abeta peptides that are less amyloidogenic and increasing CatB activity could counteract the neuropathology of this disease $[127,128]$.

Apolipoprotein E (apoE) alleles are important genetic risk factors for Alzheimer's disease (AD), which influence brain amyloid- $\beta$ peptide (Abeta) and amyloid burden. Direct intracerebral administration of lentiviral vectors expressing the three common human apoE isoforms differentially alters hippocampal Abeta and amyloid burden in mouse model of $\mathrm{AD}$ [129]. Expression of apoE4 in the absence of mouse apoE increases hippocampal Abeta [1-42] levels and amyloid burden. By contrast, expression of apoE2, even in the presence of mouse apoE, markedly reduces hippocampal Abeta burden. Thus gene delivery of apoE2 may reduce the development of neuritic plaques [129].

Recently, Kim showed that SIRT1, a human homolog of SIR2 (a gene which promotes longevity in a variety of organisms), is upregulated in mouse models for Alzheimer's disease [130]. Injection of SIRT1-expressing lentivirus in the hippocampus of the inducible p25 transgenic mice (a model of $\mathrm{AD}$ ) conferred significant protection against neurodegeneration, reduced neurodegeneration in the hippocampus, prevented learning impairment, and decreased the acetylation of the known SIRT1 substrates PGC- $1 \alpha$ and p53 [130]. Neurodegeneration induced by pathogenic proteins depends on contributions from surrounding glia. In Alzheimer's disease, NF- $\kappa \mathrm{B}$ signaling in microglia is critically involved in neuronal death induced by Abeta peptides. Stimulation of microglia with Abeta increases acetylation of RelA/p65, which regulates the NF$\kappa \mathrm{B}$ pathway. Overexpression of SIRT1 deacetylase and the addition of the SIRT1 agonist resveratrol markedly reduce NF- $\kappa \mathrm{B}$ signaling stimulated by Abeta and has strong neuroprotective effects, which support a glial loop hypothesis by demonstrating a critical role for microglial NF- $\kappa$ B signaling in Abeta-dependent neurodegeneration [131]. Microglia, the immune cells of the brain, are activated in the brain of Alzheimer's disease patients, and express the innate immune receptor toll-like receptor 2 (TLR2). Richard et al. [132] generated triple transgenic mice deficient in TLR2 and harboring a mutant human presenelin 1 and a chimeric mouse/human amyloid precursor protein (APP). TLR2 deficiency accelerated spatial and contextual memory impairments, which correlated with increased levels of Abeta [1-42] and transforming growth factor $\beta 1$ in the brain. Expression levels of N-Methyl-D-Aspartate (NMDA) receptors 1 and $2 \mathrm{~A}$ were also lower in the hippocampus of APP-TLR2 (-/-) mice. Gene therapy in cells of the bone marrow using lentivirus expressing TLR2 rescued the cognitive impairment of APP-TLR2(-I-) mice and restored the memory consolidation process disrupted by TLR2 deficiency in APP mice [132].

\section{Drug Addiction}

Drug addiction is a major public health issue. It is typically a multi-genetic brain disorder, implying combined changes of expression of several hundred genes. Addictive drugs (cocaine and amphetamines), depressants (ethanol), and opiate narcotics (heroin and morphine) are powerful reinforcers and produce their rewarding effects of euphoria or pleasure through an interaction with the mesolimbic dopamine system [133]. The dopamine $\mathrm{D}_{3}$ receptor $\left(\mathrm{D}_{3} \mathrm{R}\right)$ is an important pharmacotherapeutic target for its potential role in psychiatric disorders and drug dependence. Lentivirus-mediated manipulations of $\mathrm{D}_{3} \mathrm{R}$ levels, using local injection in the Accumbens of combinations of either $\mathrm{D}_{3} \mathrm{R}$ expressing and/or siRNAs-expressing lentiviruses induced strong behavioral changes in the locomotor stimulant effects of cocaine [134]. Suppression of $\mathrm{D}_{3} \mathrm{R}$ expression increased locomotor stimulant effects, whereas its overexpression with lentivirus-expressing $\mathrm{D}_{3} \mathrm{R}$ drastically reduced them. The latter effects could be reversed when animals were fed doxycycline, which prevented ectopic overexpression of $\mathrm{D}_{3} \mathrm{R}$ in the Accumbens [134]. In the mesolimbic dopaminergic pathway, dopamine is removed by its transporter DAT. Lentivirus-mediated overexpression of DAT in the nucleus Accumbens induced a $35 \%$ decrease in locomotor activity, which could be abolished when the same animal was fed doxycycline, whereas local inhibition of DAT in the this brain area, using lentiviruses expressing siRNAs targeted against DAT, resulted in significant hyperlocomotion activity $(72 \%$ increase over controls) [135]. $\alpha$-Synuclein binds to the dopamine and serotonin transporters (DAT and SERT), affecting their activities and their recruitment to the plasma membrane, an effect that can be modulated by $\gamma$-synuclein expression $[136,137]$. Local manipulation of either $\alpha$ - or $\gamma$-synuclein expression, by means of lentiviruses expressing either genes or siRNAs targeted against them, strongly affected cocaine-induced behavioral effects and $\gamma$-synuclein modulates cocaine-induced reinforcing and incentive effects [138, 139].

Strong molecular adaptations and plasticity within this mesolimboc dopaminergic pathway upon administration of drugs underlie a complex rewiring of neural circuitry that results in the behaviors associated with addiction [133, 140]. Little is known about the specific targets involved in this neuroadaptation process but it has been suggested that cocaine and other drugs of abuse may alter the morphology of neuronal dendrites and spines, the primary site of excitatory synapses in the brain, by means of inducing expression changes of surface molecules [133, 141]. Complex changes in expression of a number of surface axon guidance molecules have been observed upon cocaine administration, which may underlie important neuroplastic 
changes in the reward- and memory-related brain centers after drug action [142]. Local expression changes of these cues may mediate plasticity and cytoskeleton rearrangement through mechanisms similar to synaptic targeting during development. In addition, strong induction of a surface tetraspanin protein involved in cell adhesion, CD81, has been described [143-145]. Tetraspanins are scaffold proteins that integrate receptor signaling and form complexes with integrins, to mediate axon growth induced by numerous extracellular matrix proteins. Using a regulatable lentivirus bearing the rat CD81 gene under the control of a tetracycline-inducible system, Bahi et al. [146] showed that local overexpression of CD81 in this pathway, by means of doxycycline-regulatable lentiviral-mediated gene transfer into the nucleus Accumbens, induced a fourto fivefold increase in locomotor activity, which can be reversed to normal in the same animal fed doxycycline [144, 146]. Furthermore several lentiviruses expressing siRNA targeted against CD81 have been designed and CD81 gene silencing was assessed in vivo upon local, stereotaxic injection into the ventral tegmental area (VTA) or the Nucleus Accumbens (NAcc) [147]. Expression of siRNA targeted against CD81 decreased CD81-mediated locomotor activity almost back to basal levels, and could be regulated by very local and specific gene knockdown, a clear indication that drug-mediated behavioral activity is strongly modulated by this tetraspanin [147].

A similar approach was used to assess the role of other genes in drug addiction. Among these the plasminogen system is particularly intriguing. Extracellular proteolytic processes play a key function in regulating synaptic structure and function, and CNS plasticity. Among these, plasminogen activators are important mediators of extracellular metabolism, involved in remodeling events during development and regeneration in the nervous system. The generation of plasmin from its inactive precursor plasminogen is mediated by serine enzymes known as tissue-type plasminogen activator (tPA) and urokinase (uPA), and contributes to the turnover of the extracellular matrix in the CNS. Urokinase-type plasminogen activator (uPA) exerts a variety of functions during development, and is involved in learning and memory. Several tetraspanins drastically affect plasmin activity and prevent uPA binding to its receptor UPAR by promoting stable association of UPAR with specific integrins (e.g., $\alpha 5 \beta 1$ ), redistributing uPAR to focal adhesion. A screening for genes induced after drug treatment showed that urokinase plasminogen-type activator (uPA) was strongly regulated by cocaine in several paradigms of drug administration [148]. Lentiviral-mediated injection of a doxycycline-regulated uPA expression cassette, (or of its mutated form) into specific rat brain areas (Hippocampus, nucleus Accumbens and Ventral Tegmental Area) showed a dramatic, doxycycline-dependent, 10- to 12.3-fold increase in locomotor activity after cocaine administration [148]. Behavioral effects were completely abolished when uPA expression was turned off with doxycycline or when the active site of the protease was point-mutated and used as a dominant negative [148, 149]. Lentiviral-mediated overexpression of UPA in the VTA induces doxycycline-dependent expression of its receptor, uPAR, but not its inhibitor, plasminogen activator inhibitor-1 (PAI-1) [149]. Local injection of uPA-specific siRNAs expressing lentiviruses into the ventral tegmental area suppressed cocaine-induced behavioral changes associated with uPA expression [149, 150] Lentivirus-mediated overexpression of UPA in the Accumbens shell significantly augments cocaine-induced place preference, whereas its inhibition abolished the acquisition but not the expression of cocaine-induced place preference $[149,150]$. Furthermore, while this overexpression did not affect the ability of preference to be extinguished, reinstatement with a low dose of cocaine produced significantly greater preference to the cocaine-associated context. Thus once place preference had been established, and the preference extinguished, reinstatement induced by a priming dose of cocaine is facilitated by uPA. Furthermore, lentivirus-mediated overexpression of uPA induces cocaine-, but not amphetamine-mediated behavioral changes, whereas, in contrast, tPA-overexpressing animals displayed greater place preference when administered amphetamine or morphine compared to uPA-overexpressing animals [149-151]. The behavioral effects are suppressed when tPA has been silenced using specific siRNAsexpressing lentiviruses. Suppression of endogenous tPA expression in animals treated with siRNA-expressing lentiviruses also fully suppresses place preference and these animals appear to avoid the drug-associated box. In addition, lentivirus-mediated tPA overexpression delays extinction, but priming with low doses of amphetamine (not cocaine) reinstates place preference even after full extinction. Thus tPA plays an important role in acquisition of amphetamineinduced conditioned place preference but its role in place preference-expression does not seem important [151, 152]. Together these data indicate that IPA and uPA may induce distinct behaviors, which may be interpreted according to their differential pattern of activation and downstream targets. Thus, modulation of the plasminogen system in the brain might be a potential target against drugs of abuse [153].

Furthermore, the neurotrophin BDNF (brain-derived neurotrophic factor) is also involved in cocaine reward and relapse. BDNF is involved in the survival and function of midbrain dopamine neurons, mediated by its TrkB receptor. BDNF and TrkB transcripts are widely expressed in the mesolimbic pathway, including the Nucleus Accumbens (NAc) and the Ventral Tegmentum Area (VTA). Lentiviruses expressing either BDNF or TrkB enhance druginduced locomotor activity and induce sensitization in rats 
[135]. Upon local treatment, animals display enhanced cocaine-induced place preference, delayed place preference-extinction and increased reinstatement. Lentiviralmediated expression of TrkT1 (truncated form of TrkB, acting as a dominant negative) inhibits these behavioral changes. This inhibition is also observed when rats are fed doxycycline (blocking local, lentivirus-mediated gene expression) or when injected with siRNAs-expressing lentiviruses against TrkB [135]. This approach enabled to show that BDNF and TrkB-induced place preference takes place during the learning period (conditioning) whereas extinction leads to the loss of place preference. Extinction is delayed when rats are injected BDNF- or TrkBexpressing lentiviruses, whereas priming injections of cocaine reinstates it.

\section{Attention-Deficit Hyperactivity Disorder (ADHD)}

Attention-Deficit Hyperactivity Disorder (ADHD) is a neurobehavioral developmental disorder, characterized by a persistent pattern of impulsiveness and inattention, with or without a component of hyperactivity [154]. According to the dominant model, ADHD is viewed as an executive dysfunction [155-157], but alternative accounts present ADHD as a motivational dysfunction [158], arising from altered reward processes within fronto-striatal circuits [159, 160]. Comorbidity to ADHD and other impulsecontrol disorders is pathological gambling as well as common, especially compulsive buying and compulsive sexual behavior [161]. The disorder is highly heritable and arises from a combination of various genes, many of which affect dopamine transporters. Psycho-genetic studies have revealed that, among several genes involved in DAergic neuro-transmission within the reward system, one of the most significant being the dopamine transporter (DAT) [162]. Besides, candidate genes include the dopamine receptor D4 [163], dopamine $\beta$-hydroxylase [164], monoamine oxidase A, catecholamine-methyl transferase, serotonin transporter promoter, and serotonine receptors 5-HT2A and 5-HT1B [165, 166].

Adriani et al. [167] tested the role of striatal dopamine function in ADHD using lentiviruses driving the expression of DAT or siRNAs targeted against DAT mRNA in the Nucleus Accumbens of rats. These tools enabled us to evaluate behavioral changes, associated with very local DAT over-expression or suppression [167]. Accumbal DAT suppression was expected to enhance tonic DA transmission, compared to controls, whereas its over-expression would drastically reduce synaptic DA levels. To probe the resulting behavioral phenotype, animals were tested for several motivational endpoints such as seeking for novelty, intolerance to delay, and temptation to gamble [168, 169].
Whereas all knockout mice models have the major disadvantage that the gene is absent all over the CNS, lentivirus-mediated DAT manipulation is very local and only initiated in mature animals. Rats were followed both for socio-emotional profiles and for risk-seeking propensity. Elevated anxiety and affiliation toward a stranger emerged upon silencing DAT in the nucleus Accumbens, in rats stereotaxically injected with LV-expressing shRNA targeted to DAT. Interestingly, using a doxycycline-regulatable lentivirus overexpressing DAT showed that levels of playful social interaction were markedly reduced, compared to controls. These rats displayed a marked "gambling" profile (i.e., preference for a large/uncertain over a small/sure reward), which disappeared upon doxycycline-induced switch-off on DAT enhancer, and consistently reappeared with doxycycline removal [167]. This powerful tool allowed to reproduce an integrated profile in a regulatable way and shows that lentiviral vectors are suitable tools for animal models to reproduce psychiatrically relevant symptoms.

\section{Other Disorders}

In vivo gene delivery by means of lentiviral vector-mediated gene transfer has been used for assessing gene function of many other pathologies. In many cases lentiviral-mediated in vivo delivery of shRNAs targeting a major candidate has also been attempted.

\section{Rett Syndrome}

The methyl-CpG-binding protein-2 gene (Mecp2) is the causal gene of the neurodevelopmental disorder, Rett Syndrome. A rat model with a downregulated Mecp2 was established using a recombinant lentiviral vector expressing small hairpin RNA of the rat Mecp2 gene [170]. Four recombinant vectors were constructed by inserting sequences of small hairpin RNA targeting the rat Mecp2 gene. Rats were given intraventricular injections. Mecp2 mRNA was lower in the hippocampus and cerebral cortex relative to control groups. Although no typical Rett-like symptoms were observed, the neonatal rats injected with recombinant lentivirus displayed some transient neurobehavioral abnormalities during early development [170]. BDNF mRNA expression decreased in the hippocampus, supporting the hypothesis that BDNF may be a target gene of MeCP2 in the CNS [170]. Furthermore, by means of a lentivirus expressing Cre recombinase, Nelson et al. [171] showed that loss of MeCP2 function after neurodevelopment and synaptogenesis was sufficient to mimic the decrease in the frequency of spontaneous excitatory synaptic transmission seen in constitutive MeCP2 KO neurons 
[171]. Taken together, these results suggest a role for $\mathrm{MeCP} 2$ in control of excitatory presynaptic function through regulation of gene expression.

\section{Amyotrophic Lateral Sclerosis}

Amyotrophic lateral sclerosis (ALS) is a fatal neurodegenerative disease resulting in the selective death of motor neurons in the brain and spinal cord. Mutations in $\mathrm{Cu} / \mathrm{Zn}$ superoxide dismutase (encoded by $S O D 1$ ) is one of the causes of familial amyotrophic lateral sclerosis, which leads to progressive death of motoneurons through a gainof-function mechanism. RNA interference (RNAi) mediated by lentiviral vectors allows for long-term reduction in gene expression and represents an attractive therapeutic approach for genetic diseases characterized by acquired toxic properties [172]. Lentiviral vectors mediating expression of RNAi molecules specifically targeting the human $S O D 1$ gene $(S O D 1)$ have been designed and injected into various muscle groups of mice engineered to overexpress a mutated form of human SOD1 (SOD1G93A), which resulted in an efficient and specific reduction of SOD1 expression and improved survival of vulnerable motor neurons in the brainstem and spinal cord [172]. Furthermore, in SOD1G93A transgenic mice (a model for familial ALS) intraspinal injection of a lentiviral vector that produces RNAi-mediated silencing of SOD1 substantially retards both the onset and the progression rate of the disease [172, 173].

\section{Scrapie}

Prion diseases are fatal neurodegenerative diseases characterized by the accumulation of PrPSc, the infectious and protease-resistant form of the cellular prion protein (PrPC). Pfeiffer et al. [174] generated lentivectors expressing PrPC-specific shRNAs that efficiently silenced expression of the prion protein gene (Prnp) in primary neuronal cells. Treatment of scrapie-infected neuronal cells with these lentivectors resulted in an efficient and stable suppression of PrPSc accumulation. After intracranial injection, lentiviral shRNA reduced PrPC expression in transgenic mice carrying multiple copies of Prnp [174].

\section{Glioma}

Glioma cells are characterized by their invasiveness and resistance against conventional therapeutics. Telomerase activity has been suggested to be an important target for glioma treatment. Zhao et al. [175] assessed the anticancer effects of lentiviral vector-mediated siRNA knockdown of the human telomerase reverse transcriptase (hTERT) in U87MG human glioblastoma cells and in vivo. Injection of lentiviral vectors significantly inhibited the growth of preestablished macroscopic xenograft tumors. The in vivo glioma growth inhibition effect coincided with no detectable telomere length changes [2, 175]. Thus, efficient knockdown of hTERT can inhibit glioma cell proliferation and migration prior to its effect on telomere length.

\section{Spinal Cord Injury}

Injuries to the adult mammalian spinal cord often lead to severe damage to both ascending (sensory) pathways and descending (motor) nerve pathways without the perspective of complete functional recovery. Neurotrophins have emerged as promising molecules to augment neuroprotection and neuronal regeneration. Recently, lentiviral vectormediated gene transfer of neurotrophins has been tested successfully in order to promote regeneration of the injured spinal cord [176]. Furthermore, a conditioning lesion to peripheral axons of primary sensory neurons accelerates regeneration of their central axons in vivo or neurite outgrowth. Neuropoietic cytokines are also involved in this in regenerative conditioning [177]. Delivery through a lentivirus vector of ciliary neurotrophic factor to the appropriate dorsal root ganglion in rats effectively mimics the conditioning effect of peripheral nerve injury on the regeneration of dorsal spinal nerve root axons [177].

\section{Other Uses}

Finally, lentiviral-mediated gene transfer has further great potential and applications. For example, human neural progenitor cells hold great potential as an ex vivo system for delivery of therapeutic proteins to the central nervous system, because, as aggregates (neurospheres), they are capable of significant expansion. Capowski et al. [116] developed lentiviral-mediated genetic modification of human neural progenitor cells for ex vivo gene therapy, which maintains the differentiation and proliferative properties of neurosphere cultures while minimizing the amount of viral vector used and controlling the number of insertion sites per population. This method results in long-term stable expression even after differentiation of progenitor cells to neurons and astrocytes and may have great therapeutic potential. On another approach, Dittgen et al. [178] established a method for genetic manipulation and subsequent phenotypic analysis of individual cortical neurons in vivo. Lentiviral vectors were prepared for neuron-specific gene delivery from either calcium-calmodulin-dependent protein kinase II promoter or from Synapsin I promoter, optionally in combination with gene knockdown by means of U6 promoter-driven expression of short-interfering RNAs [178]. These tools may be ideally suited for analysis of gene functions in individual neurons in the intact brain. 
Similarly, Kameda developed lentiviral vectors for targeting green fluorescent protein specifically to dendritic membrane in central neurons [179]. Using a lentivirus with a neuron-specific promoter, GFP with a palmitoylation (palGFP) or myristoylation/palmitoylation site (myrGFP) was expressed in rat brain to target dendritic membranes efficiently. myrGFP tagged with the C-terminal cytoplasmic domain of low density lipoprotein receptor proved to be an excellent synthetic protein for dendritic visualization, and may be a useful tool for the morphological analysis of neuronal circuits [179]. In an even more specific approach, Santamaria developed lentiviral vector that produces shRNA targeting choline acetyl-transferase (ChAT) mRNAs and used this tool to transduce cholinergic neurons in vivo [180], resulting in reduced ChAT expression strongly and specifically in the cholinergic neurons of the medial septum in adult rats, without affecting the expression of the vesicular acetylcholine transporter. This lentiviral vector is thus a powerful tool for specific inactivation of cholinergic neurotransmission and can, therefore, be used to study the role of cholinergic nuclei in the brain.

\section{Conclusions}

RNA interference has now developed into a very powerful approach toward therapy for neural disorders [181], and many gene delivery strategies for RNAi knockdown of neuronal genes have been tested. In this review I have shown the applications of lentivirus-mediated gene transfer in the investigation of a large variety of brain disorders. As a matter of fact, lentiviral vectors are increasingly used for gene delivery to neurons and in experimental models of brain disorders. Their use in gene delivery has received greatest attention and the use of neuron-specific promoters, where introduced, enables cell-specific gene transfer in a complex system such as the brain. The development of selfinactivating lentiviruses enables also to very locally manipulate the expression of a specific gene, in a very specific and limited neuronal pathway within the brain. In addition, the development of lentiviral systems has facilitated the exogenous manipulation of RNAi in hard to transfect, postmitotic cells such as neurons. Lentiviral vectors with their high tropism for neurons offer one of the most attractive options for delivering shRNAs to the CNS, as well as to cultured neurons and neuronal cell lines in vitro. This approach has been successfully used to functionally silence genes in primary mammalian cells, stem cells and more importantly in transgenic mice, resulting in persistent knockdown of gene expression. The use of lentiviruses for stable gene silencing in brain will soon prove a powerful aid to probe gene function in vivo and for gene therapy of diseases of the central nervous system.
Lentiviral-mediated RNAi experiments in cultured mammalian neurons can be designed to address a wide variety of biological questions or to test potential therapeutic hairpins before moving to treatment trials in vivo. Indeed, potent silencing of gene expression in vitro and in vivo by lentiviral vector-based RNAi provide the tools for developing effective gene silencing therapeutics for many major brain disorders [182]. Experimental gene therapy approaches under development using this technology are well advanced today, particularly for motor disorders such as Parkinson's disease and related synucleinopathies, or Huntington's disease, dystonia or muscular dystrophy, as I have shown in this review. Besides lentivirus gene transfer has been an invaluable tool recently for evaluation of gene function in highly complex behavioral disorders such as drug addiction and attention-deficit hyperactivity disorder or in learning and cognition. Many studies also include lentiviral-mediated delivery of neurotrophic factor genes, anti-apoptotic genes, and genes that modulate neurotransmission. Clearly this technology will greatly help at a deeper understanding of these complex disorders in future studies.

\section{References}

1. Aebischer, P., \& Ridet, J. L. (2001). Recombinant proteins for neurodegenerative diseases: The delivery issue. Trends in $\mathrm{Neu}$ rosciences, 24, 533-540.

2. Zhao, C., Strappe, P. M., Lever, A. M. L., \& Franklin, R. J. M. (2003). Lentiviral vectors for gene delivery to normal and demyelinated white matter. Glia, 42, 59-67.

3. Bensadoun, J. C., Deglon, N., Tseng, J. L., Ridet, J. L., Zurn, A. D., \& Aebischer, P. (2000). Lentiviral vectors as a gene delivery system in the mouse midbrain: Cellular and behavioral improvements in a 6-OHDA model of Parkinson's disease using GDNF. Experimental Neurology, 164, 15-24.

4. Janas, J., Skowronski, J., \& Van Aelst, L. (2006). Lentiviral delivery of RNAi in hippocampal neurons. Methods in Enzymology, 406, 593-605.

5. Gascón, S., Paez-Gomez, J. A., Díaz-Guerra, M., Scheiffele, P., \& Scholl, F. G. (2008). Dual-promoter lentiviral vectors for constitutive and regulated gene expression in neurons. Journal of Neuroscience Methods, 168(1), 104-112.

6. Dillon, A. K., Fujita, S. C., Matise, M. P., Jarjour, A. A., Kennedy, T. E., Kollmus, H., et al. (2005). Molecular control of spinal accessory motor neuron/axon development in the mouse spinal cord. Journal of Neuroscience, 25(44), 10119-10130.

7. Dykxhoorn, D. M., Novina, C. D., \& Sharp, P. A. (2003). Killing the messenger: Short RNAs that silence gene expression. Nature Reviews Molecular Cell Biology, 4(6), 457-467. Review.

8. Elbashir, S. M., Lendeckel, W., \& Tuschl, T. (2001). RNA interference is mediated by 21- and 22-nucleotide RNAs. Genes and Development, 15(2), 188-200.

9. Hannon, G. J., \& Rossi, J. J. (2004). Unlocking the potential of the human genome with RNA interference. Nature, 431, 371-378.

10. Scherr, M., Battmer, K., Ganser, A., \& Eder, M. (2003). Modulation of gene expression by lentiviral-mediated delivery of small interfering RNA. Cell Cycle, 2, 251-257.

11. Buckingham, S. D., Esmaeili, B., Wood, M., \& Sattelle, D. B. (2004). RNA interference: From model organisms towards 
therapy for neural and neuromuscular disorders. Human Molecular Genetics, 13, 275-288.

12. Van den Haute, C., Eggermont, K., Nuttin, B., Debyser, Z., \& Baekelandt, V. (2003). Lentiviral vector-mediated delivery of short hairpin RNA results in persistent knockdown of gene expression in mouse brain. Human Gene Therapy, 14(18), 1799-1807.

13. Rubinson, D. A., Dillon, C. P., Kwiatkowski, A. V., Sievers, C., Yang, L., Kopinja, J., et al. (2003). A lentivirus-based system to functionally silence genes in primary mammalian cells, stem cells and transgenic mice by RNA interference. Nature Genetics, 33, 401-406.

14. Stewart, S. A., Dykxhoorn, D. M., Palliser, D., Mizuno, H., Yu, E. Y., An, D. S., et al. (2003). Lentivirus-delivered stable gene silencing by RNAi in primary cells. RNA, 9, 493-501.

15. Ventura, A., Meissner, A., Dillon, C. P., McManus, M., Sharp, P. A., Van Parijs, L., et al. (2004). Cre-lox-regulated conditional RNA interference from transgenes. Proceedings of the National Academy of Sciences of the United States of America, 101(28), 10380-10385.

16. Kunath, T., Gish, G., Lickert, H., Jones, N., Pawson, T., \& Rossant, J. (2003). Transgenic RNA interference in ES cellderived embryos recapitulates a genetic null phenotype. Nature Biotechnology, 21(5), 559-561.

17. Carmell, M. A., Zhang, L., Conklin, D. S., Hannon, G. J., \& Rosenquist, T. A. (2003). Germline transmission of RNAi in mice. Nature Structural Biology, 10, 91-95.

18. Tiscornia, G., Tergaonkar, V., Galimi, F., \& Verma, I. M. (2004). CRE recombinase-inducible RNA interference mediated by lentiviral vectors. Proceedings of the National Academy of Sciences of the United States of America, 101(19), 7347-7351.

19. Szulc, J., \& Aebischer, P. (2008). Conditional gene expression and knockdown using lentivirus vectors encoding shRNA Methods. Molecular Biology, 434, 291-309.

20. Noseworthy, J. H., Lucchinetti, C., Rodriguez, M., \& Weinshenker, B. G. (2000). Multiple sclerosis. The New England Journal of Medicine, 343, 938-952.

21. Compston, A., \& Coles, A. (2002). Multiple sclerosis. Lancet, 359(9313), 1221-1231.

22. Debouverie, M., Pittion-Vouyovitch, S., Louis, S., \& Guillemin, F. (2008). Natural history of multiple sclerosis in a populationbased cohort. European Journal of Neurology, 15(9), 916-921.

23. Rosati, G. (2001). The prevalence of multiple sclerosis in the world: An update. Neurological Sciences, 22(2), 117-139.

24. Ascherio, A., \& Munger, K. L. (2007). Environmental risk factors for multiple sclerosis. Part I: The role of infection. Annals of Neurology, 61(4), 288-299.

25. Kornek, B., \& Lassmann, H. (2003). Neuropathology of multiple sclerosis-New concepts. Brain Research Bulletin, 61, 321-326.

26. Svejgaard, A. (2008). The immunogenetics of multiple sclerosis. Immunogenetics, 60(6), 275-286.

27. International Multiple Sclerosis Genetics Consortium, Hafler, D. A., Compston, A., Sawcer, S., Lander, E. S., Daly, M. J., et al. (2007). Risk alleles for multiple sclerosis identified by a genomewide study. The New England Journal of Medicine, 357(9), 851-862.

28. Weber, F., Fontaine, B., Cournu-Rebeix, I., Kroner, A., Knop, M., Lutz, S., et al. (2008). IL2RA and IL7RA genes confer susceptibility for multiple sclerosis in two independent European populations. Genes and Immunity, 9(3), 259-263.

29. Anaya, J. M., Gómez, L., \& Castiblanco, J. (2006). Is there a common genetic basis for autoimmune diseases? Clinical and Developmental Immunology, 13(2-4), 185-195.

30. Spolski, R., Kashyap, M., Robinson, C., Yu, Z., \& Leonard, W. J. (2008). IL-21 signaling is critical for the development of type
I diabetes in the NOD mouse. Proceedings of the National Academy of Sciences of the United States of America, 105(37), 14028-14033.

31. Palacios, R., Aguirrezabal, I., Fernandez-Diez, B., Brieva, L., \& Villoslada, P. (2005). Chromosome 5 and multiple sclerosis. Journal of Neuroimmunology, 167(1-2), 1-3.

32. Richardson, J. H., Hofmann, W., Sodroski, J. G., \& Marasco, W. A. (1998). Intrabody-mediated knockout of the high-affinity IL2 receptor in primary human $\mathrm{T}$ cells using a bicistronic lentivirus vector. Gene Therapy, 5(5), 635-644.

33. Gobin, S. J., Montagne, L., Van Zutphen, M., van der Valk, P., van den Elsen, P. J., \& De Groot, C. J. (2001). Upregulation of transcription factors controlling $\mathrm{MHC}$ expression in multiple sclerosis lesions. Glia, 36, 68-77.

34. Frisullo, G., Mirabella, M., Angelucci, F., Caggiula, M., Morosetti, R., Sancricca, C., et al. (2006). pSTAT1, pSTAT3, and T-bet expression in peripheral blood mononuclear cells from relapsing-remitting multiple sclerosis patients correlates with disease activity. Journal of Neuroscience Research, 84, $1027-1036$.

35. Cannella, B., \& Raine, C. S. (2004). Multiple sclerosis: Cytokine receptors on oligodendrocytes predict innate regulation. Annals of Neurology, 55, 46-57.

36. David, M., Romero, G., Zhang, Z. Y., Dixon, J. E., \& Larner, A. C. (1993). In vitro activation of the transcription factor ISGF3 by interferon alpha involves a membrane-associated tyrosine phosphatase and tyrosine kinase. The Journal of Biological Chemistry, 268, 6593-6599.

37. Jiao, H., Berrada, K., Yang, W., Tabrizi, M., Platanias, L. C., \& Yi, T. (1996). Direct association with and dephosphorylation of Jak2 kinase by the SH2-domain-containing protein tyrosine phosphatase SHP-1. Molecular and Cellular Biology, 16, 6985-6992.

38. Frank, C., Burkhardt, C., Imhof, D., Ringel, J., Zschörnig, O., Wieligmann, K., et al. (2004). Effective dephosphorylation of Src substrates by SHP-1. The Journal of Biological Chemistry, 279, 11375-11383.

39. Massa, P. T., \& Wu, C. (1996). The role of protein tyrosine phosphatase SHP-1 in the regulation of IFN-gamma signaling in neural cells. The Journal of Immunology, 157, 5139-5144.

40. Massa, P. T., Saha, S., Wu, C., \& Jarosinski, K. W. (2000). Expression and function of the protein tyrosine phosphatase SHP-1 in oligodendrocytes. Glia, 29, 376-385.

41. Massa, P. T., Wu, C., \& Fecenko-Tacka, K. (2004). Dysmyelination and reduced myelin basic protein gene expression by oligodendrocytes of SHP-1-deficient mice. Journal of Neuroscience Research, 77, 15-25.

42. Christophil, G. P., Hudson, C. A., Gruber, R. C., Christophil, C. P., Mihai, C., Mejico, L. J., et al. (2008). SHP-1 deficiency and increased inflammatory gene expression in PBMCs of multiple sclerosis patients. Laboratory Investigation, 88, 243-255.

43. Wrzesinski, S., Séguin, R., Liu, Y., Domville, S., Planelles, V., Massa, P., et al. (2000). HTLV type 1 Tax transduction in microglial cells and astrocytes by lentiviral vectors. AIDS Research and Human Retroviruses, 16, 1771-1776.

44. Fahn, S., Bressman, S. B., \& Marsden, C. D. (1998). Classification of dystonia. Advances in Neurology, 78, 1-10.

45. Ozelius, L. J., Hewett, J. W., Page, C. E., Bressman, S. B., Kramer, P. L., Shalish, C., et al. (1997). The early-onset torsion dystonia gene (DYT1) encodes an ATP-binding protein. Nature Genetics, 17, 40-48.

46. Hanson, P. I., \& Whiteheart, S. W. (2005). AAA proteins: have engine, will work. Nature Reviews Molecular Cell Biology, 6, 519-552.

47. Hewett, J. W., Nery, F. C., Niland, B., Ge, P., Tan, P., Hadwiger, P., et al. (2008). siRNA knockdown of mutant torsinA restores 
processing through secretory pathway in DYT1 dystonia cells. Human Molecular Genetics, 17(10), 1436-1445.

48. Kustedjo, K., Bracey, M. H., \& Cravatt, B. F. (2000). Torsin A and its torsion dystonia-associated mutant forms are lumenal glycoproteins that exhibit distinct subcellular localizations. The Journal of Biological Chemistry, 275(36), 27933-27939.

49. Gonzalez-Alegre, P., \& Paulson, H. L. (2004). Aberrant cellular behavior of mutant torsinA implicates nuclear envelope dysfunction in DYT1 dystonia. Journal of Neuroscience, 24(11), 2593-2601.

50. Goodchild, R. E., \& Dauer, W. T. (2004). Mislocalization to the nuclear envelope: An effect of the dystonia-causing torsin A mutation. Proceedings of the National Academy of Sciences of the United States of America, 101, 847-852.

51. Naismith, T. V., Heuser, J. E., Breakefield, X. O., \& Hanson, P. I. (2004). TorsinA in the nuclear envelope. Proceedings of the National Academy of Sciences of the United States of America, 101, 7612-7617.

52. Bragg, D. C., Camp, S. M., Kaufman, C. A., Wilbur, J. D., Boston, H., Schuback, D. E., et al. (2004). Perinuclear biogenesis of mutant torsin-A inclusions in cultured cells infected with tetracycline-regulated herpes simplex virus type 1 amplicon vectors. Neuroscience, 125(3), 651-656.

53. Gonzalez-Alegre, P., Miller, V. M., Davidson, B. L., \& Paulson, H. L. (2003). Toward therapy for DYT1 dystonia: Allele-specific silencing of mutant TorsinA. Annals of Neurology, 53, 781-787.

54. Hewett, J., Gonzalez-Agosti, C., Slater, D., Ziefer, P., Li, S., Bergeron, D., et al. (2000). Mutant torsinA, responsible for early-onset torsion dystonia, forms membrane inclusions in cultured neural cells. Human Molecular Genetics, 9, 1403-1413.

55. Gonzalez-Alegre, P., Bode, N., Davidson, B. L., \& Paulson, H. L. (2005). Silencing primary dystonia: lentiviral-mediated RNA interference therapy for DYT1 dystonia. Journal of Neuroscience, 25(45), 10502-10509.

56. Kock, N., Allchorne, A. J., Sena-Esteves, M., Woolf, C. J., \& Breakefield, X. O. (2006). RNAi blocks DYT1 mutant torsinA inclusions in neurons. Neuroscience Letters, 395(3), 201-205.

57. Nollen, E. A., Garcia, S. M., van Haaften, G., Kim, S., Chavez, A., Morimoto, R. I., et al. (2004). Genome-wide RNA interference screen identifies previously undescribed regulators of polyglutamine aggregation. Proceedings of the National Academy of Sciences of the United States of America, 101, 6403-6408.

58. Lieberman, A. P., \& Fischbeck, K. H. (2000). Triplet repeat expansion in neuromuscular disease. Muscle and Nerve, 23, 843-850.

59. Caplen, N. J., Taylor, J. P., Statha, V. S., Tanaka, F., Fire, A., \& Morgan, R. A. (2002). Rescue of polyglutamine-mediated cytotoxicity by double-stranded RNA-mediated RNA interference. Human Molecular Genetics, 11, 175-184.

60. Xia, H., Mao, Q., Eliason, S. L., Harper, S. Q., Martins, I. H., Orr, H. T., et al. (2004). RNAi suppresses polyglutamineinduced neurodegeneration in a model of spinocerebellar ataxia. Nature Medicine, 10, 816-820.

61. Alves, S., Régulier, E., Nascimento-Ferreira, I., Hassig, R., Dufour, N., Koeppen, A., et al. (2008). Striatal and nigral pathology in a lentiviral rat model of Machado-Joseph disease. Human Molecular Genetics, 17(14), 2071-2083.

62. Lavedan, C. (1998). The synuclein family. Genome Research, 8(9), 871-880.

63. Polymeropoulos, M., Lavedan, C., Leroy, E., Ide, S. E., Dehejia, A., Dutra, A., et al. (1997). Mutation in the alpha-synuclein gene identified in families with Parkinson's disease. Science, 276(5321), 2045-2047.

64. LoBianco, C., Ridet, J. L., Schneider, B. L., Deglon, N., \& Aebischer, P. (2002). Alpha-synucleinopathy and selective dopaminergic neuron loss in a rat lentiviral-based model of Parkinson's disease. Proceedings of the National Academy of Sciences of the United States of America, 99(16), 10813-10818.

65. Fountaine, T. M., \& Wade-Martins, R. (2007). RNA interference-mediated knockdown of alpha-synuclein protects human dopaminergic neuroblastoma cells from $\mathrm{MPP}(+)$ toxicity and reduces dopamine transport. Journal of Neuroscience Research, 85(2), 351-363.

66. Sapru, M. K., Yates, J. W., Hogan, S., Jiang, L., Halter, J., \& Bohn, M. C. (2006). Silencing of human alpha-synuclein in vitro and in rat brain using lentiviral-mediated RNAi. Experimental Neurology, 198, 382-390.

67. Peng, X. M., Tehranian, R., Dietrich, P., Stefanis, L., \& Perez, R. G. (2005). Alpha-synuclein activation of protein phosphatase $2 \mathrm{~A}$ reduces tyrosine hydroxylase phosphorylation in dopaminergic cells. Journal of Cell Science, 118, 3523-3530.

68. Perez, R. G., Waymire, J. C., Lin, E., Liu, J. J., Guo, F., \& Zigmond, M. J. (2002). A role for alpha-synuclein in the regulation of dopamine biosynthesis. Journal of Neuroscience, 22, 3090-3099.

69. Alerte, T. N. M., Akinfolarin, A. A., Friedrich, E. E., Mader, S. A., Hong, C. S., \& Perez, R. G. (2008). Alpha-synuclein aggregation alters tyhrosine hydroxylase phosphorylation and immunoreactivity: Lessons from viral transduction of knockout mice. Neuroscience Letters, 435(1), 24-29.

70. Kieburtz, K., McDonald, M., Shih, C., Feigin, A., Steinberg, K., Bordwell, K., et al. (1994). Trinucleotide repeat length and progression of illness in Huntington's disease. Journal of Medical Genetics, 31(11), 872-874.

71. Gusella, J. F., Wexler, N. S., Conneally, P. M., Naylor, S. L., Anderson, M. A., Tanzi, R. E., et al. (1983). A polymorphic DNA marker genetically linked to Huntington's disease. Nature, 306, 234-238.

72. Bates, G., Harper, P., \& Jones, L. (2002). Huntington's disease (3rd ed.). Oxford: Oxford University Press.

73. Imarisio, S., Carmichael, J., Korolchuk, V., Chen, C. W., Saiki, S., Rose, C., et al. (2008). Huntington's disease: From pathology and genetics to potential therapies. Biochemical Journal, 412(2), 191-209.

74. Beal, M. F., \& Ferrante, R. J. (2004). Experimental therapeutics in transgenic mouse models of Huntington's disease. Nature Reviews Neuroscience, 5, 373-384.

75. Kirik, D., \& Björklund, A. (2003). Modeling CNS neurodegeneration by overexpression of disease-causing proteins using viral vectors. Trends in Neurosciences, 26(7), 386-392. Review.

76. Ramaswamy, S., McBride, J. L., \& Kordower, J. H. (2007). Animal models of Huntington's disease. ILAR Journal, 48(4), 356-373. Review.

77. Harper, S. Q., Staber, P. D., He, X., Eliason, S. L., Martins, I. H., Mao, Q., et al. (2005). RNA interference improves motor and neuropathological abnormalities in a Huntington's disease mouse model. Proceedings of the National Academy of Sciences of the United States of America, 102(16), 5820-5825.

78. McBride, J. L., Boudreau, R. L., Harper, S. Q., Staber, P. D., Monteys, A. M., Martins, I., et al. (2008). Artificial miRNAs mitigate shRNA-mediated toxicity in the brain: Implications for the therapeutic development of RNAi. Proceedings of the National Academy of Sciences of the United States of America, 105(15), 5868-5873.

79. Zala, D., Bensadoun, J. C., Pereira de Almeida, L., Leavitt, B. R., Gutekunst, C. A., Aebischer, P., et al. (2004). Long-term lentiviral-mediated expression of ciliary neurotrophic factor in the striatum of Huntington's disease transgenic mice. Experimental Neurology, 185(1), 26-35.

80. Zala, D., Benchoua, A., Brouillet, E., Perrin, V., Gaillard, M. C., Zurn, A. D., et al. (2005). Progressive and selective striatal 
degeneration in primary neuronal cultures using lentiviral vector coding for a mutant huntingtin fragment. Neurobiology of Diseases, 20(3), 785-798.

81. Runne, H., Regulier, E., Kuhn, A., Zala, D., Gokce, O., Perrin, V., et al. (2008). Dysregulation of gene expression in primary neuron models of Huntington's disease shows that polyglutamine- related effects on the striatal transcriptome may not be dependent on brain circuitry. Journal of Neuroscience, 28(39), 9723-9731.

82. deAlmeida, L. P., Ross, C. A., Zala, D., Aebischer, P., \& Déglon, N. (2002). Lentiviral-mediated delivery of mutant huntingtin in the striatum of rats induces a selective neuropathology modulated by polyglutamine repeat size, huntingtin expression levels, and protein length. Journal of Neuroscience, 22(9), 3473-3483.

83. Régulier, E., Trottier, Y., Perrin, V., Aebischer, P., \& Déglon, N. (2003). Early and reversible neuropathology induced by tetracycline-regulated lentiviral overexpression of mutant huntingtin in rat striatum. Human Molecular Genetics, 12(21), 2827-2836.

84. Perrin, V., Régulier, E., Abbas-Terki, T., Hassig, R., Brouillet, E., Aebischer, P., et al. (2007). Neuroprotection by Hsp104 and Hsp27 in lentiviral-based rat models of Huntington's disease. Molecular Therapy, 15(5), 903-911.

85. Popovic, N., Maingay, M., Kirik, D., \& Brundin, P. (2005). Lentiviral gene delivery of GDNF into the striatum of R6/2 Huntington mice fails to attenuate behavioral and neuropathological changes. Experimental Neurology, 193(1), 65-74.

86. Benchoua, A., Trioulier, Y., Zala, D., Gaillard, M. C., Lefort, N., Dufour, N., et al. (2006). Involvement of mitochondrial complex II defects in neuronal death produced by N-terminus fragment of mutated huntingtin. Molecular Biology of the Cell, 17(4), 1652-1663.

87. Benchoua, A., Trioulier, Y., Diguet, E., Malgorn, C., Gaillard, M. C., Dufour, N., et al. (2008). Dopamine determines the vulnerability of striatal neurons to the N-terminal fragment of mutant huntingtin through the regulation of mitochondrial complex II. Human Molecular Genetics, 17(10), 1446-1456.

88. Charvin, D., Roze, E., Perrin, V., Deyts, C., Betuing, S., Pagès, C., et al. (2008). Haloperidol protects striatal neurons from dysfunction induced by mutated huntingtin in vivo. Neurobiology of Diseases, 29(1), 22-29.

89. Cui, L., Jeong, H., Borovecki, F., Parkhurst, C. N., Tanese, N., \& Krainc, D. (2007). Transcriptional repression of PGC-1alpha by mutant huntingtin leads to mitochondrial dysfunction and neurodegeneration. Cell, 127(1), 59-69.

90. Fukui, H., \& Moraes, C. T. (2007). Extended polyglutamine repeats trigger a feedback loop involving the mitochondrial complex III, the proteasome and huntingtin aggregates. Human Molecular Genetics, 16(7), 783-797.

91. Dass, B., \& Kordower, J. H. (2007). Gene therapy approaches for the treatment of Parkinson's disease. Handbook of Clinical Neurology, 84, 291-304.

92. Déglon, N., Tseng, J. L., Bensadoun, J. C., Zurn, A. D., Arsenijevic, Y., deAlmeida, L., et al. (2000). Self-inactivating lentiviral vectors with enhanced transgene expression as potential gene transfer system in Parkinson's disease. Human Gene Therapy, 11, 179-190.

93. Dowd, E., Monville, C., Torres, E. M., Wong, L. F., Azzouz, M., Mazarakis, N. D., et al. (2005). Lentivector-mediated delivery of GDNF protects complex motor functions relevant to human Parkinsonism in a rat lesion model. European Journal of Neuroscience, 22, 2587-2595.

94. Brizard, M., Carcenac, C., Bemelmans, A. P., Feuerstein, C., Mallet, J., \& Savasta, M. (2006). Functional reinnervation from remaining DA terminals induced by GDNF lentivirus in a rat model of early Parkinson's disease. Neurobiology of Disease, 21(1), 90-101.

95. Kitada, T., Asakawa, S., Hattori, N., Matsumine, H., Yamamura, Y., Minoshima, S., et al. (1998). Mutations in the parkin gene cause autosomal recessive juvenile parkinsonism. Nature, 392, 605-608.

96. Imai, Y., Soda, M., \& Takahashi, R. (2000). Parkin suppresses unfolded protein stress induced cell death through its E3 ubiquitin-protein ligase activity. The Journal of Biological Chemistry, 275, 35661-35664.

97. Doss-Pepe, E. W., Chen, L., \& Madura, K. (2005). Alpha-synuclein and parkin contribute to the assembly of ubiquitin lysine 63-linked multiubiquitin chains. The Journal of Biological Chemistry, 280, 16619-16624.

98. Lim, K. L., Chew, K. C., Tan, J. M., Wang, C., Chung, K. K., Zhang, Y., et al. (2005). Parkin mediates nonclassical, proteasomal-independent ubiquitination of synphilin-1: Implications for Lewy body formation. Journal of Neuroscience, 25, 2002-2009.

99. Ulusoy, A., \& Kirik, D. (2008). Can overexpression of parkin provide a novel strategy for neuroprotection in Parkinson's disease? Experimental Neurology, 212(2), 258-260.

100. LoBianco, C., Schneider, B. L., Bauer, M., Sajadi, A., Brice, A., Iwatsubo, T., et al. (2004). Lentiviral vector delivery of parkin prevents dopaminergic degeneration in an alpha-synuclein rat model of Parkinson's disease. Proceedings of the National Academy of Sciences of the United States of America, 101, 17510-17515.

101. Ridet, J. L., Bensadoun, J. C., Déglon, N., Aebischer, P., \& Zurn, A. D. (2006). Lentivirus-mediated expression of glutathione peroxidase: Neuroprotection in murine models of Parkinson's disease. Neurobiology of Disease, 21(1), 29-34.

102. Vergo, S., Johansen, J. L., Leist, M., \& Lotharius, J. (2007). Vesicular monoamine transporter 2 regulates the sensitivity of rat dopaminergic neurons to disturbed cytosolic dopamine levels. Brain Research, 1185, 18-32.

103. Deierborg, T., Soulet, D., Roybon, L., Hall, V., \& Brundin, P. (2008). Emerging restorative treatments for Parkinson's disease. Progress in Neurobiology, 85, 407-432.

104. Chao, C. C., \& Lee, E. H. Y. (1999). Neuroprotective mechanism of glial cell line-derived neurotrophic factor on dopamine neurons: Role of antioxidation. Neuropharmacology, 38, 913-916.

105. Kordower, J. H., Emborg, M. E., Bloch, J., Ma, S. Y., Chu, Y., Leventhal, L., et al. (2000). Neurodegeneration prevented by lentiviral vector delivery of GDNF in primate models of Parkinson's disease. Science, 290, 767-773.

106. Jakobsson, J., \& Lundberg, C. (2006). Lentiviral vectors for use in the central nervous system. Molecular Therapy, 13, 484-493.

107. Bilang-Bleuel, A., Revah, F., Colin, P., Locquet, I., Robert, J. J., Mallet, J., et al. (1997). Intrastriatal injection of an adenoviral vector expressing glial-cell-line-derived neurotrophic factor prevents dopaminergic neuron degeneration and behavioral impairment in a rat model of Parkinson disease. Proceedings of the National Academy of Sciences of the United States of America, 94, 8818-8823.

108. Rosenblad, C., Gronborg, M., Hansen, C., Blom, N., Meyer, M., Johansen, J., et al. (2000). In vivo protection of nigral dopamine neurons by lentiviral gene transfer of the novel GDNF-family member neublastin/artemin3. Molecular and Cellular Neurosciences, 15, 199-214.

109. Georgievska, B., Kirik, D., Rosenblad, C., Lundberg, C., \& Bjorklund, A. (2002). Neuroprotection in the rat Parkinson model by intrastriatal GDNF gene transfer using a lentiviral vector. NeuroReport, 13, 75-82. 
110. Azzouz, M., Ralph, S., Wong, L. F., Day, D., Askham, Z., Barber, R. D., et al. (2004). Neuroprotection in a rat Parkinson model by GDNF gene therapy using EIAV vector. Neuroreport, $15,985-990$.

111. Palfi, S., Leventhal, L., Chu, Y., Ma, S. Y., Emborg, M., Bakay, R., et al. (2002). Lentivirally delivered glial cell line-derived neurotrophic factor increases the number of striatal dopaminergic neurons in primate models of nigrostriatal degeneration. Journal of Neuroscience, 22, 4942-4954.

112. Winkler, C., Sauer, H., Lee, C. S., \& Bjorklund, A. (1996). Short-term GDNF treatment provides long-term rescue of lesioned nigral dopaminergic neurons in a rat model of Parkinson's disease. Journal of Neuroscience, 16, 7206-7215.

113. Bjorklund, A., Kirik, D., Rosenblad, C., Georgievska, B., Lundberg, C., \& Mandel, R. J. (2000). Towards a neuroprotective gene therapy for Parkinson's disease: Use of adenovirus. AAV and lentivirus vectors for gene transfer of GDNF to the nigrostriatal system in the rat Parkinson model. Brain Research, 886, 82-98.

114. Choi-Lundberg, D. L., Lin, Q., Schallert, T., Crippens, D., Davidson, B. L., Chang, Y. N., et al. (1998). Behavioral and cellular protection of rat dopaminergic neurons by an adenoviral vector encoding glial cell line-derived neurotrophic factor. Experimental Neurology, 154(2), 261-275.

115. LoBianco, C., Déglon, N., Pralong, W., \& Aebischer, P. (2004). Lentiviral nigral delivery of GDNF does not prevent neurodegeneration in a genetic rat model of Parkinson's disease. Neurobiology of Diseases, 17(2), 283-289.

116. Capowski, E. E., Schneider, N. L., Ebert, A. D., Seehus, C. R., Szulc, J., Zufferey, R., et al. (2007). Lentiviral vector-mediated genetic modification of human neural progenitor cells for ex vivo gene therapy. Journal of Neuroscience Methods, 163, 338-349.

117. Ebert, A. D., Beres, A. J., Barber, A. E., \& Svendsen, C. N. (2008). Human neural progenitor cells over-expressing IGF-1 protect dopamine neurons and restore function in a rat model of Parkinson's disease. Experimental Neurology, 209, 213-223.

118. Caplen, A. (2000). Gene therapy for neurodegeneration. Trends in Molecular Medicine, 7, 51-55.

119. Takasugi, N., Takahashi, Y., Morohashi, Y., Tomita, T., \& Iwatsubo, T. (2002). The mechanism of gamma-secretase activities through high molecular weight complex formation of presenilins is conserved in Drosophila melanogaster and mammals. The Journal of Biological Chemistry, 277, 50198-50205.

120. Kao, S. C., Krichevsky, A. M., Kosik, K. S., \& Tsai, L. H. (2004). BACE1 suppression by RNA interference in primary cortical neurons. The Journal of Biological Chemistry, 279, 1942-1949.

121. Vassar, R. (2004). BACE 1: The beta-secretase enzyme in Alzheimer's disease. Journal of Molecular Neuroscience, 23(1-2), 105-114.

122. Burton, A. (2005). RNA inhibition of beta-secretase reverts AD in mice. Lancet Neurology, 4(11), 698.

123. Sierant, M., Kubiak, K., Kazmierczak-Baranska, J., Paduszynska, A., Kuwabara, T., Warashina, M., et al. (2008). RNA interference in silencing of genes of Alzheimer's disease in cellular and rat brain models. Nucleic Acids Symposium Series (Oxford), 52, 41-42.

124. Singer, O., Marr, R. A., Rockenstein, E., Crews, L., Coufal, N. G., Gage, F. H., et al. (2005). Targeting BACE1 with siRNAs ameliorates Alzheimer disease neuropathology in a transgenic model. Nature Neuroscience, 8(10), 1343-1349.

125. Sun, X., He, G., \& Song, W. (2006). BACE2, as a novel APP theta-secretase, is not responsible for the pathogenesis of Alzheimer's disease in Down syndrome. FASEB Journal, 20(9), $1369-1376$.
126. El-Amouri, S. S., Zhu, H., Yu, J., Marr, R., Verma, I. M., \& Kindy, M. S. (2008). Neprilysin: An enzyme candidate to slow the progression of Alzheimer's disease. American Journal of Pathology, 172(5), 1342-1354.

127. Mueller-Steiner, S., Zhou, Y., Arai, H., Roberson, E. D., Sun, B., Chen, J., et al. (2006). Antiamyloidogenic and neuroprotective functions of cathepsin B: Implications for Alzheimer's disease. Neuron, 51(6), 703-714.

128. Cole, G., \& Frautschy, S. A. (2006). Cat and mouse. Neuron, 51(6), 671-672.

129. Dodart, J. C., Marr, R. A., Koistinaho, M., Gregersen, B. M., Malkani, S., Verma, I. M., et al. (2005). Gene delivery of human apolipoprotein $\mathrm{E}$ alters brain Abeta burden in a mouse model of Alzheimer's disease. Proceedings of the National Academy of Sciences of the United States of America, 102(4), 1211-1216.

130. Kim, D., Nguyen, M. D., Dobbin, M. M., Fischer, A., Sananbenesi, F., Rodgers, J. T., et al. (2007). SIRT1 deacetylase protects against neurodegeneration in models for Alzheimer's disease and amyotrophic lateral sclerosis. EMBO Journal, 26(13), 369-379.

131. Chen, J., Zhou, Y., Mueller-Steiner, S., Chen, L. F., Kwon, H., Yi, S., et al. (2005). SIRT1 protects against microglia-dependent amyloid-beta toxicity through inhibiting NF-kappaB signaling. The Journal of Biological Chemistry, 280(48), 4036440374.

132. Richard, K. L., Filali, M., Préfontaine, P., \& Rivest, S. (2008). Toll-like receptor 2 acts as a natural innate immune receptor to clear amyloid beta 1-42 and delay the cognitive decline in a mouse model of Alzheimer's disease. Journal of Neuroscience, 28(22), 5784-5793.

133. Nestler, E. (2000). Genes and addiction. Nature Genetics, 26, 277-281.

134. Bahi, A., Boyer, F., Bussard, G., \& Dreyer, J. L. (2005). Silencing dopamine D3-receptor in the nucleus Accumbens shell in vivo induces behavioral changes in chronic cocaine delivery. European Journal of Neuroscience, 21, 3415-3426.

135. Bahi, A., Boyer, F., \& Dreyer, J. L. (2008). Cocaine-induced behavioral and reward upon lentivirus-mediated expression changes of BDNF and TrkB in the nucleus. Accumbens Psychopharmacology, 200(1), 129-139.

136. Wersinger, C., Prou, D., Vernier, P., \& Sidhu, A. (2003). Modulation of dopamine transporter function by alpha-synuclein is altered by impairment of cell adhesion and by induction of oxidative stress. FASEB Journal, 17, 2151-2153.

137. Wersinger, C., \& Sidhu, A. (2005). Disruption of the interaction of alpha-synuclein with microtubules enhances cell surface recruitment of the dopamine transporter. Biochemistry, 44, 13612-13624.

138. Boyer, F., \& Dreyer, J. L. (2007). Alpha-synuclein in the nucleus Accumbens induces changes in cocaine behavior in rats. European Journal of Neuroscience, 26(10), 2764-2776.

139. Boyer, F., \& Dreyer, J. L. (2008). The role of gamma-synuclein in cocaine-induced behavior in rats. European Journal of Neuroscience, 27(11), 2938-2951.

140. Robinson, T. E., \& Berridge, K. C. (1993). The neural basis of drug craving: An incentive-sensitization theory of addiction. Brain Research Brain Research Review, 18, 247-291.

141. Yue, Y., Chen, Z. Y., Gale, N. W., Blair-Flynn, J., Hu, T. J., Yue, X., et al. (2002). Mistargeting hippocampal axons by expression of a truncated Eph receptor. Proceedings of the National Academy of Sciences of the United States of America, 99, $10777-10782$.

142. Bahi, A., \& Dreyer, J. L. (2005). Cocaine-induced expression changes of axon guidance molecules in the adult rat brain. Molecular and Cellular Neuroscience, 28, 275-291. 
143. Halladay, A. K., Yue, Y., Michna, L., Widmer, D. A., Wagner, G. C., \& Zhou, R. (2000). Regulation of EphB1 expression by dopamine signaling. Brain Research Molecular Brain Research, 85(1-2), 171-178.

144. Brenz-Verca, M. S., Widmer, D. A. J., Wagner, G. C., \& Dreyer, J. L. (2001). Cocaine-induced expression of the tetratspanin CD81 and its relation to hypothalamic function. Molecular and Cellular Neuroscience, 17, 303-316.

145. Michna, L., Brenz-Verca, M. S., Widmer, D. A. J., Chen, S., Lee, J., Rogove, J., et al. (2001). Altered sensitivity of CD81deficient mice to neurobehavioral effects of cocaine. Molecular Brain Research, 90(1), 68-74.

146. Bahi, A., Boyer, F., Kafri, T., \& Dreyer, J. L. (2004). CD81induced behavioural changes during chronic cocaine administration: In vivo gene delivery with regulatable lentivirus. European Journal of Neuroscience, 19, 1621-1633.

147. Bahi, A., Boyer, F., Kolira, M., \& Dreyer, J. L. (2005). In vivo gene silencing of CD81 by lentiviral expression of siRNAs suppresses cocaine-induced behavior. Journal of Neurochemistry, 92, 1243-1255.

148. Bahi, A., Boyer, F., Gumy, C., Kafri, T., \& Dreyer, J. L. (2004). In vivo gene delivery of urokinase-type plasminogen activator with regulatable lentivirus induces behavioural changes in chronic cocaine administration. European Journal of Neuroscience, 20, 3473-3488.

149. Bahi, A., Boyer, F., \& Dreyer, J. L. (2006). Silencing urokinase in the ventral tegmental area in vivo induces Changes in cocaine-induced hyperlocomotion. European Journal of Neuroscience, 98, 1619-1631.

150. Bahi, A., Kusnecov, A., \& Dreyer, J. L. (2008). Effects of urokinase-type plasminogen activator in the acquisition, expression and reinstatement of cocaine-induced conditioned place preference. Behavioural Brain Research, 191(1), 17-25.

151. Bahi, A., \& Dreyer, J. L. (2008). Overexpression of plasminogen activators in the nucleus Accumbens enhances cocaine, amphetamine and morphine-induced reward and behavioral sensitization. Genes, Brain and Behavior, 7(2), 244-256.

152. Bahi, A., Kusnecov, A., \& Dreyer, J. L. (2008). The role of Tissue-type Plasminogen Activator System in amphetamineinduced conditioned place preference extinction and reinstatement. Neuropschopharmacology, 33(11), 2726-2734.

153. Yan, Y., Yamada, K., Mizoguchi, H., Noda, Y., Nagai, T., Nitta, A., et al. (2007). Reinforcing effects of morphine are reduced in tissue plasminogen activator-knockout mice. Neuroscience, 146(1), 50-59.

154. Dulcan, M. (1997). Practice parameters for the assessment and treatment of children, adolescents, and adults with attentiondeficit/hyperactivity disorder. American Academy of Child and Adolescent Psychiatry. Journal of the American Academy of Child and Adolescent Psychiatry, 36(Suppl 10), 85S-121S.

155. Doyle, A. E. (2006). Executive functions in attention-deficit/ hyperactivity disorder. The Journal of Clinical Psychiatry, 67(Suppl 8), 21-26. Review.

156. Castellanos, F. X., Sonuga-Barke, E. J., Milham, M. P., \& Tannock, R. (2006). Characterizing cognition in ADHD: Beyond executive dysfunction. Trends in Cognitive Sciences, 10(3), 117-123.

157. Willcutt, E. G., Pennington, B. F., Olson, R. K., Chhabildas, N., \& Hulslander, J. (2005). Neuropsychological analyses of comorbidity between reading disability and attention deficit hyperactivity disorder: In search of the common deficit. Developmental Neuropsychology, 27(1), 35-78.

158. Sonuga-Barke, E. J. (2005). Editorial. Journal of Child Psychology and Psychiatry, 46(3), 225-226.

159. Sagvolden, T., \& Sergeant, J. A. (1998). Attention deficit/ hyperactivity disorder-from brain dysfunctions to behaviour. Behavioural Brain Research, 94(1), 1-10. Review.
160. Oades, R. D. (1998). Frontal, temporal and lateralized brain function in children with attention-deficit hyperactivity disorder: A psychophysiological and neuropsychological viewpoint on development. Behavioural Brain Research, 94(1), 83-95.

161. Black, D. W., \& Moyer, T. (1998). Clinical features and psychiatric comorbidity of subjects with pathological gambling behavior. Psychiatric Services, 49(11), 1434-1439.

162. Comings, D. E. (2001). Clinical and molecular genetics of ADHD and Tourette syndrome. Two related polygenic disorders. Annals of the New York Academy of Sciences, 931, 50-83.

163. Swanson, J. M., Flodman, P., Kennedy, J., Spence, M. A., Moyzis, R., Schuck, S., et al. (2000). Dopamine genes and ADHD. Neuroscience and Biobehavioral Reviews, 24(1), 21-25.

164. Smith, K. M., Daly, M., Fischer, M., Yiannoutsos, C. T., Bauer, L., Barkley, R., et al. (2003). Association of the dopamine beta hydroxylase gene with attention deficit hyperactivity disorder: Genetic analysis of the Milwaukee longitudinal study. American Journal of Medical Genetics Part B: Neuropsychiatric Genetics, $119 B(1), 77-85$.

165. Roman, T., Rohde, L. A., \& Hutz, M. H. (2004). Polymorphisms of the dopamine transporter gene: Influence on response to methylphenidate in attention deficit-hyperactivity disorder. American Journal of Pharmacogenomics, 4(2), 83-92.

166. Oades, R. D. (2008). Dopamine-serotonin interactions in attention-deficit hyperactivity disorder (ADHD). Progress in Brain Research, 172, 543-565.

167. Adriani, W., Boyer, F., Gioiosa, L., Macrì, S., Dreyer, J. L., \& Laviola, P. (2009). Increased impulsive behavior and gambling temptation following lentivirus-mediated DAT overexpression in rats' nucleus Accumbens. Neuroscience, 159(1), 47-58.

168. Laviola, G., Macrì, S., Morley-Fletcher, S., \& Adriani, W. (2003). Risk-taking behavior in adolescent mice: Psychobiological determinants and early epigenetic influence. Neuroscience and Biobehavioral Reviews, 27(1-2), 19-31.

169. Adriani, W., \& Laviola, G. (2006). Delay aversion but preference for large and rare rewards in two choice tasks: Implications for the measurement of self-control parameters. BMC Neuroscience, 7, 52.

170. Jin, J., Bao, X., Wang, H., Pan, H., Zhang, Y., \& Wu, X. (2008). RNAi-induced down-regulation of Mecp2 expression in the rat brain. International Journal of Developmental Neuroscience, 26, 457-465.

171. Nelson, E. D., Kavalali, E. T., \& Monteggia, L. M. (2006). MeCP2-dependent transcriptional repression regulates excitatory neurotransmission. Current Biology, 16(7), 710-716.

172. Raoul, C., Abbas-Terki, T., Bensadoun, J. C., Guillot, S., Haase, G., Szulc, J., et al. (2005). Lentiviral-mediated silencing of SOD1 through RNA interference retards disease onset and progression in a mouse model of ALS. Nature Medicine, 11(4), 423-428.

173. Ralph, G. S., Radcliffe, P. A., Day, D. M., Carthy, J. M., Leroux, M. A., Lee, D. C. P., et al. (2005). Silencing mutant SOD1 using RNAi protects against neurodegeneration and extends survival in an ALS model. Nature Medicine, 11(4), 429-433.

174. Pfeifer, A., Eigenbrod, S., Al-Khadra, S., Hofmann, A., Mitteregger, G., Moser, M., et al. (2006). Lentivector-mediated RNAi efficiently suppresses prion protein and prolongs survival of scrapie-infected mice. Journal of Clinical Investigation, 116, 3204-3210.

175. Zhao, P., Wang, C., Fu, Z., You, Y., Cheng, Y., Lu, X., et al. (2008). Lentiviral vector mediated siRNA knockdown of hTERT results in diminished capacity in invasiveness and in vivo growth of human glioma cells in a telomere length-independent manner. International Journal of Oncology, 31(2), 361-368. 
176. Hendriks, W. T. J., Ruitenberg, M. J., Blits, B., Boer, G. J., \& Verhaagen, J. (2004). Viral vector-mediated gene transfer of neurotrophins to promote regeneration of the injured spinal cord. Progress in Brain Research, 146, 451-476.

177. Wu, D., Zhang, Y., Bo, X., Huang, W., Xiao, F., Zhang, X., et al. (2007). Actions of neuropoietic cytokines and cyclic AMP in regenerative conditioning of rat primary sensory neuron. Experimental Neurology, 204(1), 66-76.

178. Dittgen, T., Nimmerjahn, A., Komai, S., Licznerski, P., Waters, J., Margrie, T. W., et al. (2004). Lentivirus-based genetic manipulations of cortical neurons and their optical and electrophysiological monitoring in vivo. Proceedings of the National Academy of Sciences of the United States of America, 101, 18206-18211.

179. Kameda, H., Furuta, T., Matsuda, W., Ohira, K., Nakamura, K., Hioki, H., et al. (2008). Targeting green fluorescent protein to dendritic membrane in central neurons. Neuroscience Research, 61(1), 79-91.

180. Santamaria, J., Khalfallah, O., Sauty, C., Brunet, I., Sibieude, M., Mallet, J., et al. (2008). Silencing of choline acetyltransferase expression by lentivirus-mediated RNA interference in cultured cells and in the adult rodent brain. Journal of Neuroscience Research, online Sept 19.

181. Crittenden, J. R., Heidersbach, A., \& McManus, M. T. (2007). Lentiviral strategies for RNAi knockdown of neuronal genes. Current Protocols in Neuroscience, 5, 5-26.

182. Porras, G., \& Bezard, E. (2008). Preclinical development of gene therapy for Parkinson's disease. Experimental Neurology, 209(1), 72-81. 